Aus der Abteilung Unfallchirurgie, Plastische und Wiederherstellungschirurgie (Prof. Dr. med. K.M. Stürmer)

im Zentrum Chirurgie

der Medizinischen Fakultät der Universität Göttingen

\title{
Untersuchung der Frakturheilung bei Osteoporose unter Einwirkung von Östrogen und Alendronat an ovarektomierten Ratten
}

\section{INAUGURAL - DISSERTATION}

\author{
zur Erlangung des Doktorgrades \\ für Zahnheilkunde \\ der Medizinischen Fakultät \\ der Georg-August-Universität zu Göttingen \\ vorgelegt von \\ Ann-Kristin Lippelt, geb. Hörster \\ aus \\ Duisburg
}

Göttingen 2011 
Dekan: $\quad$ Prof. Dr. med. C. Frömmel

$\begin{array}{ll}\text { I. Berichterstatter: } & \text { Priv.-Doz. Dr. med. E. Stürmer } \\ \text { II. Berichterstatter/in: } & \text { Prof. Dr. H. Siggelkow } \\ \text { III. Berichterstatter/in: } & \text { Prof. Dr. R. Mausberg }\end{array}$

Tag der mündlichen Prüfung: 02.04.2012 
1 EINLEITUNG

1.1 Ätiologie und Klassifikation der Osteoporose............................................................................ 2

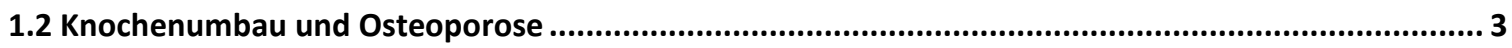

1.2.1 Mikroarchitektur und Stoffwechsel des normalen Knochens .......................................................

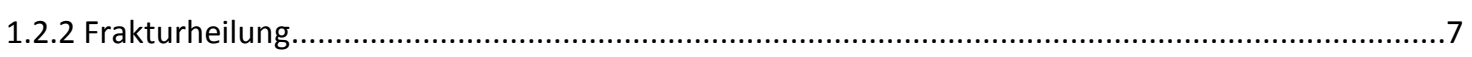

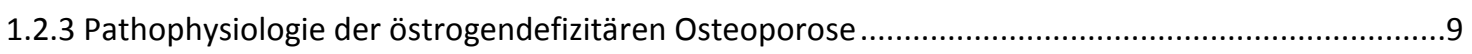

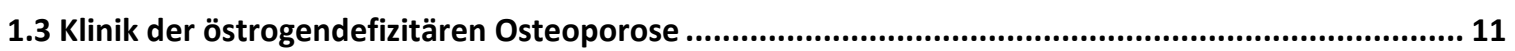

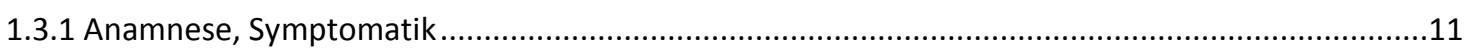

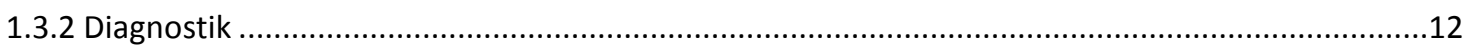

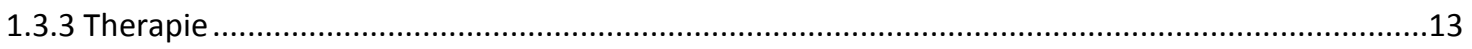

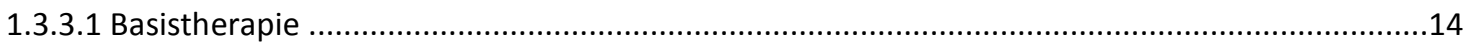

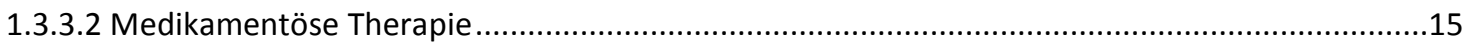

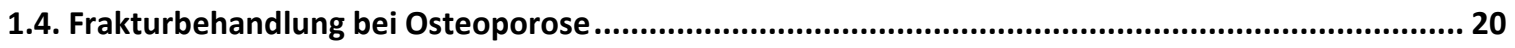

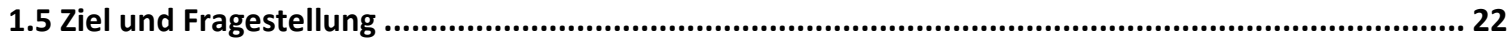

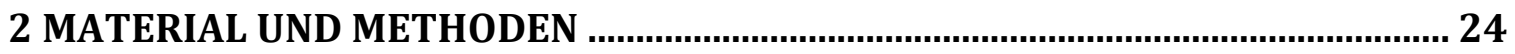

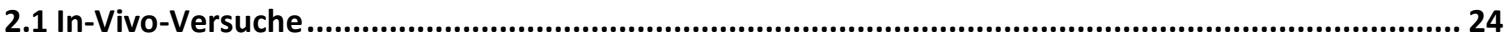

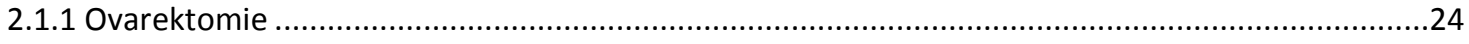

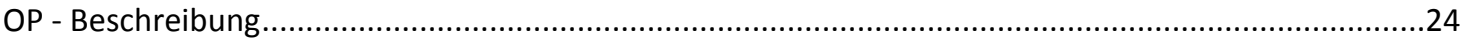

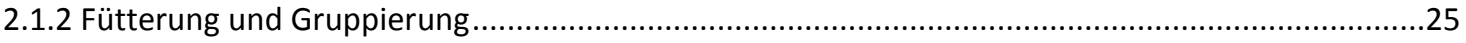

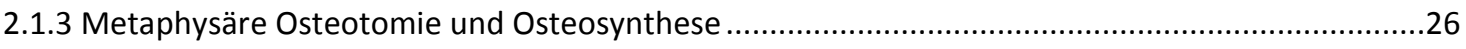

2.1.4 Zusätzliche Maßnahmen im Rahmen der Versuchszeit ...............................................................27

2.2 Versuchsende

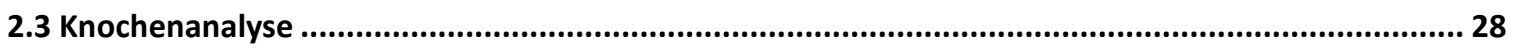

2.3.1 Biomechanische Untersuchung der metaphysären Tibia ........................................................28

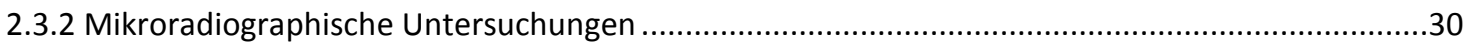

2.3.2.1 Herstellung der Präparate ..................................................................................................

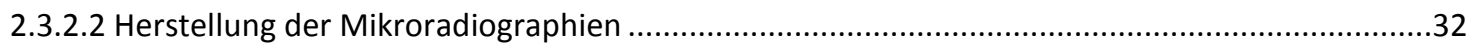

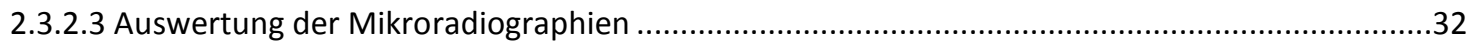




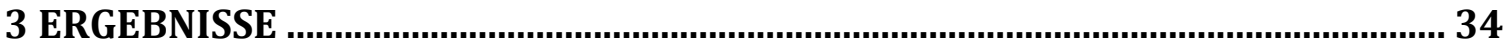

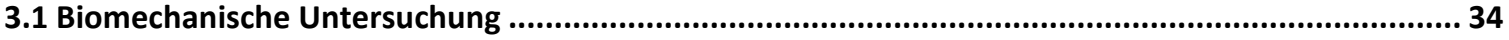

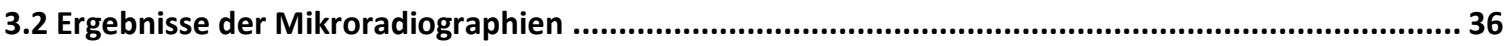

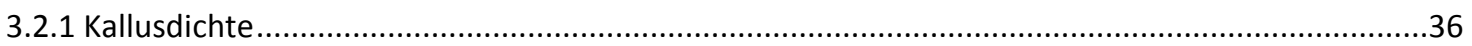

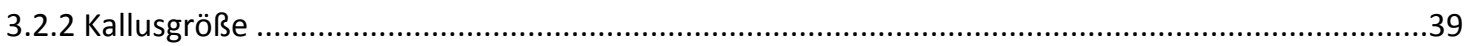

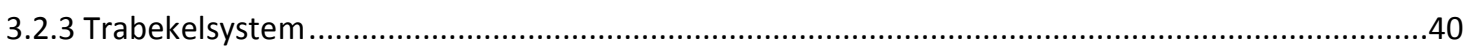

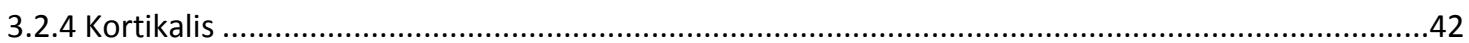

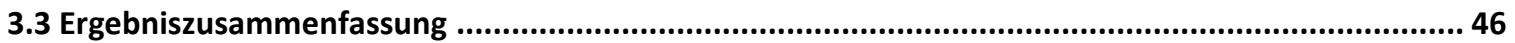

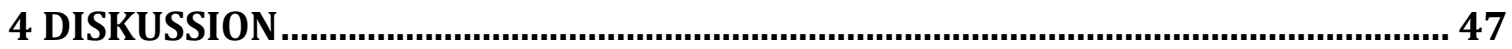

4.1 Die osteoporotische Fraktur als medizinisches und sozio-ökonomisches Problem .........................47

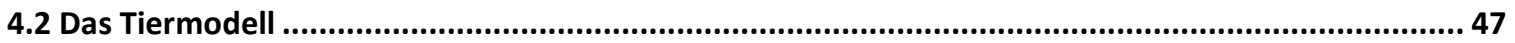

4.3 Knochenheilung unter Östrogensubstitution......................................................................... 49

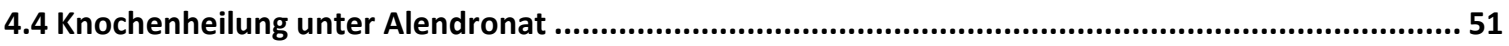

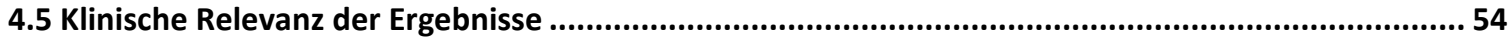

4.6 Bezug der Untersuchungen zur Zahnmedizin..........................................................................56

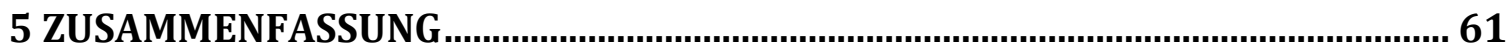

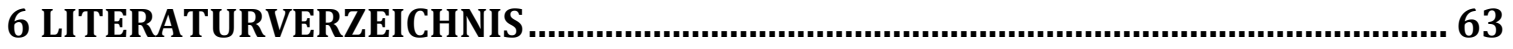

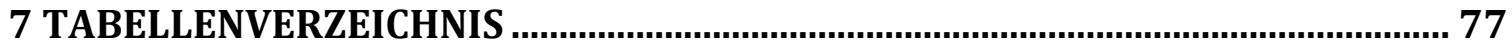

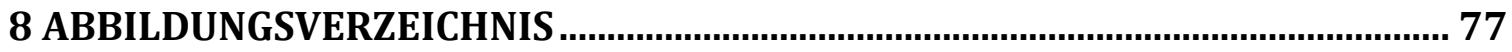




\section{Einleitung}

Osteoporose ist eine chronische Skeletterkrankung, welche durch eine Verminderung der Knochenmasse und eine Störung der Knochenmikroarchitektur charakterisiert ist (Pfeilschifter 2003). Der mit einer Demineralisation einhergehende Strukturverlust des Knochens führt zu einem Missverhältnis zwischen Belastung und Belastbarkeit mit daraus resultierender Frakturneigung (Pollähne und Hinne 2001).

Obwohl diese Erkrankung erst in den letzten Jahrzehnten zunehmend in das Bewusstsein der Öffentlichkeit rückte, existiert sie offenbar schon seit langem. Bei Untersuchungen an ägyptischen Mumien fanden sich deutliche Hinweise für eine bereits vor 4000 Jahren existente osteoporoseartige Verminderung der Knochensubstanz; seit dem Mittelalter ist die Osteoporose im Volksmund als „Knochenschwund" bekannt .

Allein in Deutschland leben heute ca. 8 Millionen Menschen mit einer symptomatischen Osteoporose; der dadurch bedingte finanzielle Aufwand für unser Gesundheitssystem wurde bereits vor einigen Jahren - mit offenbar steigender Tendenz - auf 10 Milliarden Euro geschätzt (Götte und Dittmar 2001). Die WHO (World Health Organization) zählt die Osteoporose zu den 10 bedeutendsten Volkskrankheiten (Pfeilschifter 2003). Einige Zahlen mögen diese Situation weiter konkretisieren: die Wahrscheinlichkeit, eine Wirbelkörperfraktur zu erleiden, steigt ab dem 60sten Lebensjahr um das 20 -Fache, in Bezug auf eine Schenkelhalsfraktur um das 50 -Fache (Wüster 1997); ca. ein Viertel der Patienten mit osteoporosebedingter Schenkelhalsfraktur stirbt innerhalb eines Jahres, darüber hinaus bleiben viele Menschen auf Dauer pflegebedürftig mit allen Problemen notwendiger Reha-Maßnahmen, Heimversorgung und familiärer Wiedereingliederung (Minne und Pfeifer 2003). Mit steigender Lebenserwartung ist hier eine weitere Verschärfung der Problematik zu erwarten (DAGO 1996).

Unabhängig von der volkswirtschaftlichen Bedeutung erleiden die einzelnen Betroffenen einen deutlichen Verlust an Lebensqualität: ein durch Schmerzen geprägter Alltag bei herabgesetzter Mobilität - verbunden mit gesellschaftlicher Isolierung - ist die Konsequenz. So gilt es unter gleichermaßen finanziellen wie humanitären Gesichtspunkten Prophylaxe, Diagnostik und Therapie der Osteoporose zu verbessern. 


\section{1 Ätiologie und Klassifikation der Osteoporose}

Die Ursachen für das Entstehen einer Osteoporose sind außerordentlich zahlreich, wodurch sich prinzipiell eine Klassifizierung unter verschiedensten Gesichtspunkten rechtfertigen ließe. Es hat sich angesichts dieser ätiologischen Vielfalt allerdings bewährt, eine für den klinischen Alltag praktikable Einteilung in ,primäre" und „,sekundäre" Arten der Osteoporose vorzunehmen (Franke et al. 1996). Der Unterschied besteht darin, dass für die erste Form der Osteoporose bestimmte Lebensumstände des betroffenen Individuums ursächlich sind, nicht aber eigentliche Krankheiten, die zweite aber ausgelöst wird durch an anderer Stelle des Organismus existente Erkrankungen, die dann unter anderem auch den Knochen beeinträchtigen können. In diesem Fall steht die Behandlung der Grunderkrankung im Vordergrund der Therapie.

Die primäre Osteoporose steht in engem Zusammenhang mit dem Alter, der hormonellen Regulation und dem Kalziumstoffwechsel. Dabei ist der postmenopausale Östrogenabfall ein ganz entscheidender ursächlicher Faktor. Des Weiteren kann man zwischen der primären Osteoporose Typ I und der primären Osteoporose Typ II unterscheiden. Bei der Typ I Osteoporose ist überwiegend der spongiöse Anteil der Knochen postmenopausaler Frauen und bei der Typ II Osteoporose sowohl der spongiöse als auch der kortikale Knochen von meist über 70 jährigen Frauen und Männern betroffen.

Bei den restlichen Osteoporosepatienten können verschiedene Krankheiten die Entstehung einer Osteoporose begünstigen. Man spricht dann von einer „sekundären Osteoporose", ausgelöst durch z. B. Störung des Cortisonstoffwechsels, Geschlechtshormonmangel beim Mann, Störung des Kalziumstoffwechsels oder Schilddrüsenüberfunktion. Auch eine Steroidtherapie, Diabetes und rheumatische Erkrankungen können die Entstehung von Osteoporose beeinflussen, ebenso wie eine Laktoseintoleranz oder chronische Verdauungsstörungen.

Eine solche sehr übersichtliche und damit praktikable Einteilung hat auch statistische Vorteile: ca. 95\% der Osteoporoseerkrankungen lassen sich unter diesen Gesichtspunkten als ,primär" einstufen, nur ca. 5\% der sekundären Form zuordnen (Lin und Lane 2004). 


\section{Klassifizierungsschema unter diesen Gesichtspunkten:}

\begin{tabular}{|c|c|}
\hline Primäre Osteoporose: & Sekundäre Osteoporose: \\
\hline Idiopathische Osteoporose Jugendlicher & Hypercortisolismus \\
\hline Postmenopausale Osteoporose (Typ I) & Hypogonadismus \\
\hline \multirow[t]{8}{*}{ Senile Osteoporose } & Hyperthyreose \\
\hline & Hyperparathyreoidismus \\
\hline & Diabetes mellitus Typ I und II \\
\hline & Malabsorption \\
\hline & Anorexia nervosa \\
\hline & Genetische Schäden \\
\hline & Medikamentöse Nebenwirkungen \\
\hline & Immobilisation \\
\hline
\end{tabular}

Tab. 1: Klassifizierungsschema der primären und sekundären Osteoporose

Allen für das Entstehen der Osteoporose denkbaren Krankheitsursachen ist eine negative Einwirkung auf den Knochenstoffwechsel gemeinsam, wobei häufig das Kalzium im pathophysiologischen Mittelpunkt steht.

\subsection{Knochenumbau und Osteoporose}

\subsubsection{Mikroarchitektur und Stoffwechsel des normalen Knochens}

Das Knochensystem erfüllt zwei Hauptfunktionen: es dient dem Körper als biomechanische Stütze und als Mineraldepot (Debrunner 1994). Für beide Eigenschaften wesentlich sind Knochenzellen, welche vor allem in den die knöchernen Strukturen eng umschließenden Knochenhüllen lokalisiert sind. Diese Zellen sichern die sowohl für die Architektur als auch den Stoffwechsel essentielle reaktive Potenz, welche es dem Organismus erlaubt, sich auf die verschiedenen Umweltbedingungen sowohl mechanisch, als auch biologisch einzustellen.

Die Architektur des Knochens richtet sich nach der jeweiligen lokalen Beanspruchung und gewährleistet hohe Belastbarkeit bei möglichst geringem Materialaufwand (Clark et al. 1975). Der zur Anpassung an unterschiedliche Anforderungen erforderliche ständig 
vor sich gehende Umbau wird während des Wachstums als „Modelling", später als „Remodelling" bezeichnet (Bartl 2001). Die Folge ist der Aufbau kortikaler und spongiöser Strukturen für lokale Bereiche unterschiedlicher Beanspruchung (Link 1997). Kortikalis und Spongiosa unterscheiden sich nicht in ihrer Zusammensetzung, wohl aber in Dichtigkeit und Anordnung der Knochenhartsubstanz. Auch bestehen Unterschiede in der Gefäßversorgung und damit der Zellanordnung. So ergibt z.B. der aus einem plattenartig angeordneten Trabekelwerk von ca. $120 \mu \mathrm{m}$ Dicke bestehende metaphysär spongiöse Knochen gegenüber der Kortikalis nicht nur erhöhte Stabilität, sondern auch eine verbesserte Reaktivität pro Flächeneinheit durch eine größere Zahl an Gefäßen und Zellen (Bartl 2001; Link 1997). Messbar wird eine solche Differenz am OberflächenMassen-Quotienten, welcher am spongiös- trabekulären Knochen gegenüber dem kortikalen Knochen etwa das Zehnfache beträgt.

Skelettbereiche mit einem hohen Spongiosaanteil (z.B. Wirbelkörper, Fersenbein, Schlüsselbein) nehmen aufgrund ihres Aufbaus gegenüber Knochen mit kortikalen Strukturen (lange Röhrenknochen) vermehrt am Metabolismus teil (Bartl 2001). Dieser betrifft überwiegend den Kalziumstoffwechsel: der Knochen ist mit einem Anteil von 99\% der bei weitem größte Kalziumspeicher des Organismus. Die mineralisierte Knochensubstanz besteht zu 50\% aus anorganischem Material, zu 25\% aus organischer Grundsubstanz (Matrix) und zu 25\% aus Wasser. Der Aktivitätsgrad der Knochenzellen entscheidet über den Zustand des lokalen Stoffwechsels und damit das strukturelle Ergebnis; alle unter 1.1. genannten Einflussfaktoren wirken sich damit direkt auf Form und Funktionalität des gesamten Skeletts aus.

Die zelluläre Ausstattung des Knochens besteht aus 3 verschiedenen Zelltypen, mit jeweils unterschiedlichen Aufgaben:

\section{Osteoblasten}

Osteoblasten stammen von mesenchymalen Vorläuferzellen ab, welche sich wiederum aus mesodermalen Keimbahnzellen entwickeln (Aubin 2001). Sie sind verantwortlich für den Knochenaufbau und damit für die Beseitigung von Strukturdefiziten. Diese haben ihre Ursache in einer lokalen Verminderung der Knochensubstanz, den Resorptionslakunen. Wie die Aktivierung der Aufbautätigkeit im Einzelnen vor sich geht, 
ist nicht endgültig geklärt; anhand von Mäuseversuchen konnte im Blut der Versuchstiere ein „Core Binding Transcription Factor - Runx 2“ differenziert werden, welcher essentiell für die Funktionsaufnahme der Osteoblasten zu sein scheint (Komori 1997, Otto F 1997). Eine wichtige Rolle spielen offenbar auch zuvor osteoklastär entstandene Knochenabbauprodukte, welche die Osteoblasten stimulieren - unter Umständen auch Veränderungen der Mikrozirkulation und damit der lokalen Sauerstoffversorgung (Basset 1972). Im Zentrum der Funktion steht dabei die Sekretion von organischen Substanzen überwiegend Kollagen Typ I - welche als Osteoid die Matrix für die ca. 10 Tage später beginnende Einlagerung von Hydroxylapatitkristallen bilden (Komori 1997, Otto 1997). Die Anordnung des gebildeten Kollagens ist typisch für die später resultierende Knochenstruktur (Schenk 1978 a). Das verkalkende Osteoid wird dann ortsständiger Knochensubstanz aufgelagert und verstärkt somit deren Volumen. Nach Beendigung ihrer Funktion verbleiben die Osteoblasten als ruhende Zellen auf der Knochenoberfläche; durch adäquate Reize können sie dann jederzeit wieder aktiviert werden, sobald im Rahmen des physiologischen Remodelling, bei krankhaftem Knochenverlust oder aber nach Frakturen, die Notwendigkeit dazu besteht (Wüster und Ziegler 1999, Bord 1996). Sind die ruhenden Osteoblasten durch neugebildete Matrix eingeschlossen, werden sie zu Osteozyten.

\section{Osteoklasten}

Sie sind Antagonisten der Osteoblasten, bauen nicht mehr verwendbaren Knochen ab und bereiten den lokalen Knochenaufbau vor. Osteoklasten sind mehrkernige Zellen, welche wahrscheinlich im Rahmen ihrer Aktivitätsaufnahme aus der Verschmelzung von mononukleären Einzelzellen entstehen und reich an lysosomalen Enzymen sind. Das Signal zur Tätigkeitsaufnahme liegt ganz allgemein im Vorhandensein abbaupflichtiger Knochengrundsubstanz; die Ursachen für eine solche Abbaupflicht liegen entweder in einer osteozyten - oder durchlutungsbedingt auftretenden lokalen Grundsubstanznekrose (Brookes 1960). Osteoklastenaktivität stellt in der Regel die erste Gewebsantwort auf einen knochenspezifischen Reiz dar (Frost 1969). Während des Prozesses der Knochenresorption werden zunächst Wasserstoffionen erzeugt, welche das umgebende Knochenmaterial anlösen; anschließend werden die im Zellinneren vorgehaltenen 
lysosomalen Enzyme sezerniert, wodurch die organische Knochenmatrix zersetzt wird. Die frei werdenden Mineralbestandteile werden in die Blutbahn abgegeben. Knochenerneuerung beginnt in der Regel mit osteoklastärem Abbau und konsekutiver Lyse kleiner Knochenareale (Pietschmann und Peterlik 1999). Die Tiefe der so entstehenden Knochenlakunen (Howship-Lakunen) beträgt unter physiologischen Verhältnissen ca. $60 \mu \mathrm{m}$; anschließend wird der Abbau beendet mit entsprechenden Signalen an die nun tätig werdenden Aufbauzellen (Link 1997). Wird die Osteoklastentätigkeit ausserhalb des physiologischen Remodellings in Gang gesetzt, endet sie erst, wenn der initiierende Reiz nicht mehr besteht.

\section{Osteozyten}

Sie sind in die Hartsubstanz eingemauert und wahrscheinlich für die Erhaltung der Vitalität derselben zuständig. Osteozyten bilden sich aus in die Grundsubstanz eingeschlossenen Osteoblasten, behalten prinzipiell auch deren Funktion - jedoch bei deutlich erniedrigtem Umsatz (Knese 1979). Sie sind über feine Knochenkanäle (gap junctions) miteinander und mit der benachbarten Oberfläche verbunden (Aarden 1994). Dadurch ist eine adäquate Reaktionsfähigkeit auf biologische und biomechanische Reize möglich (Doty 1981, Rawlinson 1995). Chemische Botenstoffe, wie „Insulin - like growth - factor" und „Glukose-6-phosphat" scheinen eine wichtige Rolle zu spielen. An eine normale Funktionstätigkeit der Osteozyten sind die Eigenschaften der Hartsubstanz gekoppelt, welche den normalen „Turn-Over" des Knochens ohne unphysiologischen Anoder Abbau garantieren.

Das exakte funktionelle Zusammenspiel der 3 beschriebenen Knochenzellen sichert die normal belastbare Knochenstruktur. Von erheblicher zusätzlicher Bedeutung dabei sind allerdings auf die Knochenzellen regulativ einwirkende Blutbestandteile, welche diese entweder stimulieren oder hemmen können. Kumulativ - ohne angesichts der Komplexität der Vorgänge auf deren Wirkung im Einzelnen eingehen zu können - seien hier genannt: Parathormon, Thyroxin, Calcitonin, Insulin, Cortison und Wachstumshormone. Auf die Bedeutung des Östrogens in diesem Zusammenhang wird im Folgenden speziell eingegangen (siehe 1.2.3). Über- oder Unterproduktion dieser einzelnen Substanzen bewirkt bei entsprechendem Ausmaß am Knochen sichtbare und 
auch klinisch fassbare Veränderungen, welche bei hemmender Wirkung im Rahmen der o.a. Osteoporoseklassifizierung als „sekundär" eingeordnet werden.

\subsubsection{Frakturheilung}

Frakturen bedeuten lokale Zerstörung der betroffenen Knochensubstanz einschließlich Schädigung der zugehörigen Blutgefäße. Neben der klinisch fassbaren Belastungsinsuffizienz entstehen Mikrozirkulationsstörungen im Bruchbereich mit lokaler, azidotischer Stoffwechsellage (Allgöwer 1964). Der Organismus ist gefordert, aus dieser Situation mittels den dafür vorgesehenen Reparaturmechanismen - beim Menschen u. U. auch therapeutischer Hilfe von aussen - den Normalzustand schnellstmöglich wiederherzustellen.

Das Ziel dieses Reparationsvorganges ist es, den frakturbedingt entstandenen Defekt im Knochensystem mit neu gebildetem Material zu füllen. Die dazu erforderlichen Knochenzellen werden nach unmittelbar posttraumatisch beginnender Kapillarsprossung aktiviert; Osteoklasten bauen frakturnah durch Störung der Mikrozirkulation entstandene Nekrosezonen ab und bereiten so den einige Tage später beginnenden Substanzaufbau vor. Dieser unterscheidet sich allerdings von den Abläufen im Zusammenhang mit dem physiologischen „Turn-over", da die alleinige Anlagerung von Osteoid an ortsständige Substanz quantitativ für eine schnelle Defektfüllung nicht reicht. Eine solche bedeutet daher nur einen Begleiteffekt des Heilungsvorganges, durch welchen frakturbenachbarte Kortikalis - und Spongiosastrukturen verstärkt werden. Immerhin beeinflusst dadurch aber das zum Zeitpunkt der Entstehung der Verletzung lokal vorhandene Ausmaß an Knochengewebe einschließlich der zugehörigen Gefäße die Heilung. Der wesentliche Beitrag zur Defektüberbrückung entstammt aber der Bildung des Kallusgewebes. Dabei kommt es zur stufenweisen Ausdifferenzierung von im Bruchbereich befindlichen Bindegewebsstrukturen: ausgehend vom interfragmentären Hämatom kommt es zur Einsprossung von Fibroblasten, mit ihrer Hilfe zur Bildung von Bindegewebe, unter mechanischem Einfluss zur Umwandlung desselben in Knorpel und durch Verkalkung des Knorpels letztlich zur Entstehung von tragfähigem Geflechtknochen (Eitel et al. 1976, Schenk 1978 b). Dieser Vorgang ist dann bis zum Erreichen der erwünschten Belastbarkeit je nach genetischen Vorgaben des betroffenen Organismus innerhalb 
weniger Wochen bis Monate abgeschlossen, wobei sich die endgültige Verfestigung des neu gebildeten Gewebes noch längere Zeit hinziehen kann. Ausmaß und Festigkeit des Kallusgewebes werden so zum Gradmesser effektiver Knochenheilung; darüber hinaus ist eine solche auch an der Quantität des den direkten Frakturbereich benachbarten Knochens zu erkennen, messbar an Kortikalis- und Trabekeldicke. Die Abläufe im Rahmen dieser „sekundären" Knochenheilung sind an Kortikalis und Spongiosa prinzipiell ähnlich; Unterschiede finden sich allerdings in Bezug auf die lokalen Durchblutungsverhältnisse des betroffenen Knochengewebes, da spongiöser / trabekulärer Knochen insoweit gegenüber der Kortikalis deutlich bevorzugt ist.

Operative Maßnahmen zur Stabilisierung von Frakturen sollen die Heilungsvorgänge am Knochen optimieren, durch Ausrichtung der Fragmente Fehlheilungen verhindern und den Heilverlauf begleitende Beschwerden mindern. Unter experimentellen Bedingungen lassen sich so auch Heilungsverläufe standardisieren. Osteosynthesen bedeuten aber immer einen Eingriff in die normalen pathophysiologischen Abläufe. Das erhöhte Stabilitätsausmaß vermindert zwangsläufig Relativbewegungen der Frakturenden und beeinflusst damit die davon abhängige Kallusbildung. Erreicht man als Operateur optimale Bedingungen, kann es dann zur kalluslosen, „primären" Knochenheilung kommen: dabei hat dann das Kallusgewebe keine Bedeutung für die Wiederherstellung der Stabilität mehr, diese wird ausschließlich über direkte Kontaktheilung zwischen den operationsbedingt adaptierten Fragmentenden erzielt. Naturgemäß ist eine solche Heilung auch auf postoperative Störungsfreiheit angewiesen; die Stabilität der Osteosynthese muss bis zur endgültigen Heilung so hoch sein, dass Störkräfte im Bruchbereich vermieden werden. Somit bedeutet im Umkehrschluss das Auftreten von Kallusgewebe nach stabiler Osteosynthese immer einen Hinweis darauf, dass entweder intra- oder postoperativ der erwünschte Idealzustand nicht erreicht werden konnte; im Tierversuch ist dieses in der Regel bedingt durch fehlende postoperative Entlastung des Operationbereiches. 


\subsubsection{Pathophysiologie der östrogendefizitären Osteoporose}

Für die Aufrechterhaltung einer normalen Knochenbilanz ist ein ausgeglichenes Verhältnis von Knochenresorption und Knochenformation bedeutungsvoll. Visualisiert wird dies durch die Knochendichte. Diese wiederum ist ein Maß für den Kalksalzgehalt. Die maximale Knochendichte wird beim Menschen zwischen dem 25. und 30. Lebensjahr erreicht; anschließend wird die Knochenbilanz negativ und es entsteht ein durchschnittlicher Knochenverlust von 1\% pro Jahr - in Ausnahmefällen steigt dieser bis auf 5\% pro Jahr an (Scheidt-Nave et al. 2003). Einer möglichst hohen Knochendichte kommt wesentliche Bedeutung zu: je günstiger die Ausgangssituation, um so geringer die Osteoporosegefahr beim Auftreten von Risikofaktoren.

Eine Osteoporose entsteht, wenn über längere Zeit mehr Knochen abgebaut als erneuert wird. Man unterscheidet Osteoporoseformen mit erhöhtem Knochenumsatz (,high turnover"), bei denen die Aktivität der Osteoklasten gegenüber den normalen Osteoblasten erhöht ist, von solchen mit einem verminderten Knochenumsatz („low turnover"), bei denen die Osteoklastenaktivität normal, aber die Knochenneubildung durch die Osteoblasten vermindert ist (Pietschmann 1999).

Östrogen ist ein Sexualhormon und wirkt dem Entstehen einer Osteoporose entgegen; als wirksamster Bestandteil ist das 17 - beta - estradiol anzusehen. Es wird im Ovar unter Einwirkung von FSH gebildet und wirkt auf Geschlechtsorgane, Gehirn, Darm, Haut und Knochen. Bei - besonders postmenopausal bedingtem - Östrogendefizit wird am Knochen die Tätigkeit der Osteoklasten gesteigert und damit Knochenabbau provoziert. Im Sinne einer Mittlerfunktion wirken dabei osteolytische Zytokine (Interleukin - 1 ; Interleukin - 6 ; TNF - alpha), welche allgemeine Bedeutung für die Zelldifferenzierung haben und offenbar die mehrkernigen Osteoklasten sowohl in Bezug auf Zahl als auch auf Aktivität besonders stark beeinflussen. Die Zahl der Zielzellen auf welche das Hormon im jeweiligen Knochengewebsabschnitt einwirken soll, ist für den Effekt entscheidend. Diese Zielzellen exprimieren in Bezug auf das 17-beta - Estradiol zwei verschiedene Rezeptoren, ER-alpha und ER-beta, welche sowohl in Osteoblasten, als auch in Osteoklasten vorhanden sind (Green et al. 1986), dabei allerdings antagonistisch wirken. Somit wird auch eine anteilig osteoporotische Wirkung auf eine hormonmangelbedingte 
Osteoblastenhemmung zurückgeführt (Benninghoff und Drenckhahn 1994, Ringe 1995, Manolagas und Jilka 1995, Löffler u. Petrides 1998). Von den Rezeptoren hat für den Knochen der ER - beta die erheblich größere Bedeutung. Sowohl Hormonmangel als auch Rezeptorinsuffizienz können zusammenfassend Einfluss auf die Knochenbilanz haben.

Postmenopausaler Hormonmangel steigert damit durch Osteoklastenaktivierung den Substanzabbau. Entsprechend der hier vorbestehend hohen Zelldichte sind spongiöse Bereiche besonders betroffen. Da der Knochenumsatz erhöht ist, wird diese Osteoporoseform auch als „High - Turnover" - Osteoporose bezeichnet (Pietschmann und Peterlik 1999). Morphologisch fassbare Defizite am Trabekelsystem sind die Folge mit Veränderungen von Form und Zahl, Abstand und Kreuzungspunkten der einzelnen Trabekel; dieses lässt sich auch vorteilhaft experimentell nutzen, um das Ausmaß einer existenten Osteoporose oder auch die Effektivität bestimmter anti-osteoporotischer Substanzen zu überprüfen (Lane et al. 2003, Gasser et al. 2005, Yao et al. 2005). Im fortgeschrittenen Zustand kommt es dann durch osteoklastär bedingte Bildung von bis zu $150 \mu \mathrm{m}$ tiefen Resorptionslakunen zur lokalen Perforation der metaphysären Knochenbälkchen (Delling und Vogel 1992). Es entstehen an diesen frei endende Anteile, welche zur Kraftübertragung nicht mehr geeignet sind. Die Stabilität des Knochens nimmt exponentiell ab, darüber hinaus wird den Osteoblasten das morphologische Trabekelnetz zum Anlegen neuen Knochens entzogen (Delling und Vogel 1992). Weniger der absolute Substanzverlust ist also entscheidend, vielmehr sind es die strukturellen Schäden, welche bei nur minimaler, wiederkehrender Gewalteinwirkung zur Kontinuitätsdurchtrennung des betroffenen Knochenabschnittes - und damit zur schleichenden Fraktur - führen können. Die Perforationsfrequenz korreliert mit dem klinischen Ausmaß der Osteoporose (Link 1997). Die osteoporosebedingten Veränderungen am kortikalen Knochen sind deutlich geringer. Die Ursache ist in der gegenüber spongiösem Gewebe pro Flächeneinheit geringeren Zellzahl zu sehen. Daher kommt es im Rahmen der Osteoporose hier auch nicht $\mathrm{zu}$ relevanten Strukturveränderungen, sondern nur zu einer Ausdünnung der Kortikalis - messbar an der Dicke. Auch dieses Phänomen ist durch Messungen experimentell nutzbar. Klinische Bedeutung hat die Manifestation der Osteoporose an der knöchernen Diaphyse kaum, da - 
bevor diese sich bemerkbar machen könnten - bereits Schäden an der Metaphyse auftreten, welche den Krankheitsverlauf bestimmen.

\subsection{Klinik der östrogendefizitären Osteoporose}

Für Ärzte, Patienten und Wissenschaftler werden seit Jahren alle relevanten Daten zur Osteoporose, ihrer Prophylaxe und Therapie in einer Leitlinie erfasst und fortlaufend weiterentwickelt. Die letzte Fortschreibung entstammt dem Jahre 2009. Darin enthaltene Details können als medizinischer Standard gelten; sie werden daher im Folgenden auch als wesentlicher Informationshintergrund benutzt; Herausgeber ist der „DVO = Dachverband Osteologie" (DVO 2009). Der Inhalt dieser Leitlinie stimmt mit Angaben der WHO von 1994 überein, demzufolge ca. 30\% aller Frauen nach der Menopause die Form der postmenopausalen Osteoporose entwickeln, gemessen an einer altersentsprechenden Vergleichspopulation (Häussler et al. 2006). Nach Einschränkung der Ovarialfunktion kommt es dabei zu einem entsprechenden Hormonabfall im Organismus, durch welchen - neben anderen organischen Veränderungen - ein klinisch relevantes Defizit der Knochensubstanz hervorgerufen wird, welches es zur Einleitung einer kausalen Therapie zu erfassen gilt. (s. 1.2.3)

\subsubsection{Anamnese, Symptomatik}

Auch wenn durch das Hormondefizit vielfältige, klinisch wesentliche Veränderungen im weiblichen Organismus hervorgerufen werden, sind die durch den Knochenverlust bedingten Krankheitserscheinungen besonders eingreifend. Da der Substanzverlust selbst zunächst keine Beschwerden bereitet, bleibt die Erkrankung häufig solange unerkannt und unbehandelt, bis eine Fraktur aufgetreten ist. „Fraktur" bedeutet allerdings nicht in jedem Fall eine Kontinuitätstrennung des Knochens nach entsprechender Gewalteinwirkung, sondern typisch sind "schleichende" Frakturen. Dabei entstehen durch die osteoporosebedingte Rarefizierung des spongiösen Knochens allein schon mittels muskulärer Einwirkung im Rahmen von Alltagsbewegungen Zusammenbrüche des Trabekelsystems mit Instabilitäten und Deformierungen, welche von erheblichen Beschwerden begleitet sind. Betroffen ist dabei vorzugsweise die Wirbelsäule - aber auch die Metaphyse verschiedener Extremitätenabschnitte; Patientinnen mit chronischen 
Rückenbeschwerden gilt insoweit besondere Aufmerksamkeit. Statistisch ist von Bedeutung, dass für Frauen mit anamnestisch bereits bekannter Wirbelfraktur ein deutlich höheres Risiko besteht, in der Folgezeit auch eine hüftnahe Fraktur zu erleiden (Minne und Pfeifer 2003). Im postmenopausalen Alter derartige Zusammenhänge zu beachten, ist daher wichtig. Die Ermittlung weiterer, allgemein knochensubstanzmindernder Details muss dieses in Form der Erstellung eines Risikoprofils (Bewegungsarmut, Sturzverhalten, Ernährung, Genussmittelmissbrauch, Medikamente usw.) ergänzen.

\subsubsection{Diagnostik}

\section{Bildgebung}

Bei entsprechendem Verdacht gilt es, einen solchen zu erhärten bzw. zu entkräften. Neben den üblichen klinisch - allgemeinen Maßnahmen kommen dabei technischen Methoden die entscheidende Bedeutung zu. Röntgennativ- und spezielle Schichtaufnahmen (pQCT) erbringen in Bezug auf bereits eingetretene Strukturveränderungen präzise Befunde, können allerdings keine quantitativen Aussagen zum Ausmass der Osteoporose machen. Neben den schmerzbedingt betroffenen Skelettabschnitten werden dabei auch sinnvollerweise weitere, für das Auftreten einer Osteoporose typische Risikobereiche erfasst. Im Mittelpunkt steht die Feststellung des knöchernen Kalksalzgehaltverlustes mittels Knochendichtemessung. Das heute gültige Standardverfahren nennt sich DXA (Dual-X-Ray-Absorptiometry). Dabei wird für Referenzbereiche - meist Wirbelsäule oder Hüftgelenk - die knöcherne Absorption von Röntgenstrahlen geringer Dosierung gemessen. Erfasst wird ein dimensionsfreier Wert (T-Wert), welcher ein Maß für die Abweichung vom Normalen darstellt. Als „normal" wird eine 30 - jährige Person gleichen Geschlechtes bezeichnet. Ist der T - Wert der untersuchten Person bis zu 1, entspricht er der Norm. Eine Osteoporose wird konstatiert, wenn der gemessene Wert unter dem -2,5-Fachen liegt. Da ältere Menschen häufig diesen Wert erreichen, wird eine „Krankmachung" der Bevölkerung vermieden, indem man einen zusätzlichen Bezug (Z-Wert) zu einer geschlechtsgleichen, gleichaltrigen Person herstellt. 


\section{Blut/ Serumuntersuchung}

Basislaborwerte bei der Osteoporosediagnostik bringen Erkenntnisse in Bezug auf das Vorliegen einer primären oder sekundären Osteoporose, sie gehören damit zur obligatorischen Routine (Pallamar und Friedrich 2005). Des Weiteren dienen diese Werte zur Differenzierung zwischen entzündlichen, hämatologischen und malignen Prozessen

und können auch Aufschluss über im Rahmen der Osteoporosediagnostik wichtige Knochenumsatzmarker geben: in Studien an postmenopausalen Frauen wurde, unabhängig von der Knochenmineraldichte, eine Assoziation zwischen erhöhtem Frakturrisiko und erhöhten Knochenumsatzmarkern festgestellt (Garnero et al. 1996, Garnero et al. 2000).

Die wichtigsten Knochenmarker sind:

- Marker der Knochenformation

Osteocalcin, Alkalische Phosphatase des Knochens, Prokollagen-Typ-1-NPropeptid

- Marker der Knochenresorption

Desoxypyridinolin (DPD), N- bzw. C-terminales Crosslink-Telopeptid des Typ-1Kollagens (CTX bzw. NTX).

Bei einem Anstieg der Knochenresorptionsparameter ist das allgemeine Frakturrisiko unabhängig von der Knochenmasse um den Faktor 2 (Delmas et al. 2000), bei postmenopausalen Frauen mit osteoporotischen Knochenmineraldichtewerten sogar um den Faktor 4-5 erhöht (Garnero et al. 1996). Im Rahmen der Osteoporosetherapie werden diese Parameter vorwiegend zur Beobachtung des Therapieerfolges genutzt, sie können allerdings auch für die Feststellung des Therapiebeginns bei unklarer Diagnose herangezogen werden (Delmas et al. 2000)

\subsubsection{Therapie}

Osteoprotektive Maßnahmen werden angesichts häufig verspätet gestellter Diagnosen erst längere Zeit nach Erreichen der „peak bone mass“ vorgenommen und dienen dann 
bei nicht mehr optimaler Knochenkonstellation mehr der Therapie als der Prophylaxe. Andererseits bedeuten „therapeutische" Maßnahmen immer auch gleichzeitig eine Prophylaxe weiteren Knochenabbaus und besonders des Eintretens von Frakturen. Wenn im Folgenden von therapeutischen Maßnahmen gesprochen wird, beinhalten sie in diesem Sinne immer auch Gesichtspunkte der Prävention. Es scheint dabei auch nicht notwendig, hier „Primärprävention" = Verhinderung weiteren Knochenabbaus bei noch ausreichender Substanz, „Sekundärprävention" = Verhinderung einer Erstfraktur bei bereits nachgewiesener Osteoporose und „Tertiärprävention" = Verhinderung weiterer Frakturen nach schon eigetretener Erstfraktur voneinander zu trennen. Die basistherapeutischen und spezifisch-medikamentösen Maßnahmen gelten gleichermaßen - allenfalls mit graduellen Unterschieden.

\subsubsection{Basistherapie}

Dem Erhalt eines funktionsfähigen Organismus gelten ganz allgemeine Verhaltensweisen, welche auch für das Skelettsystem Bedeutung haben. Dazu gehören eine ausgewogene Ernährung, das Vermeiden von Suchtstoffen und ausreichende Bewegung. Besteht das Risiko des Auftretens einer Osteoporose, muss versucht werden, den Kalziumgehalt des Knochens zu optimieren. Dazu muss eine Aufnahme von 1g Kalzium / Tag gewährleistet sein - sinnvollerweise wird eine solche durch die Gabe von 1000 IE Vit. D3 ergänzt, wodurch die Kalziumaufnahme in den Knochen erleichtert wird. Alle sonstigen Medikamente sind daraufhin zu überprüfen, ob sie prinzipiell osteoporosefördernd sind (z. B. Kortison).

Von Bedeutung sind - bes. im fortgeschrittenen Alter - allgemeine Maßnahmen zur Sturzprophylaxe. Wenn auch das schleichende Auftreten von Frakturen der Wirbelsäule so nicht vermieden werden kann, lassen sich doch durch Arrangieren der häuslichen Umgebung und Schutzvorrichtungen am Körper (Hüftprotektoren) Sicherheiten einbauen. Auch im Alter lassen sich darüber hinaus den Bewegungsapparat kräftigende physiotherapeutische Maßnahmen durchführen; wichtig ist allerdings, dass sie - wie alle basistherapeutischen Vorgehensweisen - in ihrer Effektivität auf Langzeitwirkung angelegt sind und damit hohen Einsatz und eine hohe Kompliance bei Betroffenen und Betreuern voraussetzen. 
Sind Schmerzmedikamente erforderlich, dürfen diese möglichst keine kreislaufnegativen Eigenschaften haben; individuelles Vorgehen ist notwendig, wobei primär NSAIDs (z.B. Diclofenac) und Opioide (z.B. Sevredol) zum Einsatz kommen.

\subsubsection{Medikamentöse Therapie}

Bei der medikamentösen Beeinflussung der Osteoporose wird versucht, möglichst kausal zu therapieren; dieses gilt gleichermaßen für primäre und sekundäre Formen. Insoweit stehen zunächst Medikamente im Mittelpunkt, durch welche jeweils unter pathophysiologischen Gesichtspunkten ein direkter Einfluss auf die Ursache der Erkrankung erwartet werden kann - weiterhin werden dann allgemein knochenaufbauende Substanzen verwendet. Für die Östrogenmangelinduzierte Osteoporose sind damit das Östrogen und das Bisphosphonat relevant.

\section{Östrogen}

17-beta-Estradiol stellt die wirksamste Komponente der im Körper vorhandenen Östrogene dar. Es entfaltet seine Wirkung als im Ovar gebildetes weibliches Geschlechtshormon im wesentlichen an den Geschlechtsorganen selbst, darüber hinaus aber auch an vielen anderen Gewebsstrukturen (Darm, Leber, Haut, Gehirn, Knochen, Knorpel). Es wirkt auf Rezeptoren ein, welche sich in Zielzellen befinden; das Kombinationsprodukt aus Hormon und Rezeptor beeinflusst über den jeweiligen Zellkern die zellspezifische Reaktion, welche sich am Knochen im Substanzaufbau äussert (s. dazu 1.2.3.). Dementsprechend wirkt sich ein - z.B. postmenopausal entstandenes Hormondefizit klinisch als Osteoporose aus.

Der Versuch ist naheliegend, die so entstandenen klinischen Symptome mittels Substitution zu beseitigen. Derartige Therapiemaßnahmen wurden auch etabliert, welches die Vielzahl der Präparate (z.B. in Deutschland zugelassen: Dermestril, Estraderm, Estradot, Estramon, Estreva, Estrifan, Estring, Estronorm, Fem7, Osmil, Sequidot, u.a.) zeigt. Es gelten unterschiedliche Applikationsweisen, Dosierungen und spezielle Indikationen, welche den Bereich der eigentlichen Osteoporosetherapie z.T. weit überschreiten. Gemeinsam ist allerdings allen ein entsprechend dem Wirkungsbereich des 
17-beta-Estradiols weitgefächerter Einfluss auf den gesamten weiblichen Organismus, welcher in bestimmten Bereichen sogar als unphysiologisch bezeichnet werden kann. So entstehen z.B. an der Uterusschleimhaut funktionelle Zustandsbilder der Dauerhypertrophie, welche mit der Gabe von Gestagenen beseitigt werden müssen, um einen zyklusähnlichen Rhythmus aufrechtzuerhalten. Unter Berücksichtigung dessen kam es auch zur Entwicklung von Kombinationspräparaten aus beiden Hormonen.

Die zunächst etablierte Östrogentherapie im Rahmen einer manifesten oder drohenden postmenopausalen Osteoporose wurde dementsprechend in den letzten Jahren auch durch mehrere klinische Studien belastet und zwar in Bezug auf tatsächlich statistisch relevante, mit dieser Therapie in Zusammenhang stehenden Nebenwirkungen. Es wurde sowohl in der randomisierten Studie der WHI vom Juli 2002, als auch in der „Million Women Study“ vom August 2003 gehäuft schwerwiegende Nebenwirkungen wie Mammakarzinome, kardiovaskuläre Risiken und thromboembolische Risiken, besonders im Falle einer Kombinationstherapie mit Östrogen und Progesteron diagnostiziert (Beral 2003). Folgt man diesen, muss vor jedem langfristigen Einsatz der Hormonsubstitution eine individuelle Nutzen- Risikoabwägung erfolgen.

Um die in Hinsicht auf die Osteoporosetherapie - und somit auch die Frakturprophylaxe erwünschte Möglichkeit des Östrogeneinsatzes nicht zu verlieren, war und ist es notwendig, nebenwirkungsärmere Präparate zu finden, oder aber die Dosierungen bzw. die Behandlungsdauer zu verkürzen. Einen Ansatz dazu bildet das mittlerweile am Markt befindliche „Menostar", welches per Pflaster applizierbar ist und mit $14 \mu \mathrm{g}$ 17-betaEstradiol pro Tag eine Halbierung der sonst therapienotwendigen Wirksubstanz aufweist. 


\section{Bisphosphonate}

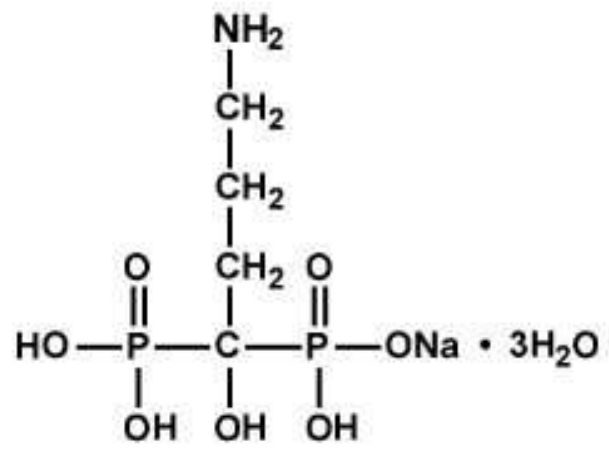

\section{Abb. 1: Strukturformel von Alendronat}

Bisphosphonate sind Abkömmlinge der Phosphonsäure, bei denen sich 2 Phosphonatgruppen über ein C-Atom mit einem organischen Rest verbinden. Die spezifischen Eigenschaften resultieren im Wesentlichen aus Strukturunterschieden in den Seitenketten, von denen biologische Aktivität und Interaktion mit intrazellulären Molekülen abhängt. Es gibt dementsprechend mehrere, klinisch nutzbare Substanzen, wobei man pharmakologisch N-haltige (Amino-phosphonate: Alendronsäure, Ibandronsäure, Clodronsäure, Zoledronsäure) von N-freien (Etidronsäure, Pamidronsäure, Tiludronsäure, Risedronsäure) unterscheidet. Die medikamentöse Wirkung aller Bisphosphonate beruht auf ihrer Eigenschaft, den Kalzium - Metabolismus zu beeinflussen; dieses führt $\mathrm{zu}$ einer Verdichtung der Knochensubstanz bei Erniedrigung des Kalziumspiegels im Blut. Der Mechanismus wird als zweifach wirksam beschrieben: zum einen bindet sich Bisphosphonat unter Bindung von Kalziumphosphat an körpereigene Mineralsalze, lagert sich so der Knochenoberfläche an und verstärkt diese; zum Zweiten schädigt es die Osteoklasten durch Hemmung eines für deren Aktivität wesentlichen Enzyms (Farnesylpyrophosphat-Synthase) wodurch der normal weiter laufende, osteoblastär gebundene Knochenaufbau für eine positive Knochenbilanz sorgt. Diese beiden Wirkmechanismen machen diese Substanzen zu geeigneten Therapeutika bei vorliegender Osteoporose. 
Bisphosphonate sind dementsprechend zur Behandlung der Osteoporose zugelassen und zwar in Form mehrerer Salzabkömmlinge der o. a. Säuren. Sie sind überwiegend oral zu applizieren, für einzelne Medikamente existieren auch Zubereitungen für intravenöse Applikation. Die Bioverfügbarkeit liegt nur bei einigen Prozent, auf normale Nierentätigkeit ist bei Rezeptur streng zu achten. Sie sind schwer resorbierbar und schädigen im Rahmen der Magen - Darm - Passage bei verlängertem Kontakt oder bei Vorerkrankungen das Endothel des Magen - Darmtraktes - entsprechende Vorgaben bei der Einnahme sind daher wesentlich. Der Kalziumspiegel muss regelmäßig überwacht werden, da er durch Bisphosphonatgabe negativ beeinflusst werden kann; ggf. sind substitutive Maßnahmen notwendig, auch Kombinationspräparate zum gleichzeitigen Kalziumersatz sind im Handel.

Bisphosphonate bilden aber trotz dieser klinischen Nachteile seit Jahren einen wesentlichen Pfeiler in der medikamentösen Osteoporosetherapie. In verschiedenen Studien konnte deren frakturrisikovermindernde, teilweise auch schmerzlindernde, Wirkung klinisch nachgewiesen werden.

Alendronat, Ibandronat und Risedronat werden dem Evidenzgrad A zugeordnet. Nach DVO - Leitlinie gelten sie als Mittel der ersten Wahl. Neben der Osteoporose sind auch osteolytisch wirkende Knochentumoren positiv beeinflussbar, wobei teilweise höhere und auch parenterale - Dosierungsvorgaben gelten.

Hier die Auflistung einiger im Handel erhältlicher Präparate, welche den einzelnen Substanzgruppen entstammen. Alle haben ähnliche Wirkmechanismen, sind aber als unterschiedlich in Bezug auf Indikation, Dosierung und Nebenwirkungen einzustufen und besitzen auch unterschiedliche Zulassungen. Das in unserer Studie verwendete Alendronat gehört nach heutiger Erkenntnis zu den effektivsten Mitteln in der Osteoporosetherapie, besonders auch in der Menopause. Seine Dosierungsvorschrift erlaubt die tägliche (1 x $10 \mathrm{mg})$ und auch die wöchentliche Zufuhr (1 x $70 \mathrm{mg})$, womit man eine Reduktion der Nebenwirkungen erreichen möchte. 


\section{Auflistung der Präparate:}

\begin{tabular}{|l|l|}
\hline Wirkstoff & \multicolumn{1}{|c|}{ Handelsname } \\
\hline Alendronat: & Fosamax \\
Ibandronat: & Bonviva \\
Clodronat: & Ostac \\
Zolendronat: & Zometa \\
Etidronat: & Didronel \\
Pamidronat: & Aredia \\
Tiludronat: & Skelid \\
Risedronat: & Actonel \\
\hline
\end{tabular}

Tab. 2: Bisphosphonate und deren Handelsnamen

Chlodronate, Zolendronate und Pamidronate werden parenteral verabreicht. Bei oraler Einnahme muss aufgrund mangelnder Resorption ein Wirkverlust einkalkuliert werden, währenddessen bei parenteraler Medikation im Umkehrschluss das Risiko einer überschießenden Reaktion am Knochen mit lokaler Hypertrophie und den damit verbundenen negativen Folgen (Nekrose, Bruchgefahr) steigt.

\section{Weitere Osteoporosepharmazeutika}

Substanzen, welche eine östrogenartige, positive Wirkung auf den Knochenstoffwechsel haben ohne mit deren schwerwiegenden Nebenwirkungen belastet zu sein, sind SERMs (Selektive Östrogen - Rezeptor - Modulatoren). Es handelt sich dabei nicht um Hormone, aber über die gleichen Knochenrezeptoren wirkende Antiresorptiva mit der Folge einer Normalisierung der erhöhten Knochenabbaurate. Östrogenrezeptoren in anderen Organen werden nur gering beeinflusst, sodass Nebenwirkungen - besonders in Form von Brustkrebs - deutlich verringert werden können.

Die Medikamente des Wirkstoffs Raloxifen (Evista) dürfen allerdings nur bei Frauen angewandt werden, welche keine relevante eigene Östrogenproduktion mehr aufweisen, da ansonsten in den knochenfernen Rezeptoren eine konkurrierende Wirkung auftreten würde. Studien in Bezug auf die Wirksamkeit existieren (Ettinger et al. 1999). 
Auch bestimmte pflanzliche Stoffe (Phytoöstrogene) haben antiosteoporotische Wirkung. Man könnte sie als „natürliche SERMs" bezeichnen, da ihre Wirkung auf den Knochenstoffwechsel offenbar den SERMs ähnelt. Z.B. finden sich solche Wirksubstanzen in größerer Zahl in der Sojapflanze. Obwohl Publikationen in Bezug auf die Wirksamkeit bestehen, und man von einer nebenwirkungsarmen Behandlung sprechen kann, sind die Phytoöstrogene allerdings bis heute nicht als echte Therapiealternative zu den o.a. Substanzen zu sehen (Zhang et al. 2005).

\subsection{Frakturbehandlung bei Osteoporose}

Frakturheilung funktioniert problemlos, solange im Verletzungsbereich genügend reaktionsfähige knöcherne Substanz zur Verfügung steht und bestimmte biomechanische Voraussetzungen erfüllt sind. Da Osteoporose lokalen Knochenverlust bedeutet, kann dadurch eine in adäquater Zeit vollzogene Heilung in Frage gestellt werden. Frakturen treten also nicht nur leichter ein, sondern heilen auch schlechter. Dies gilt es bei der Therapieplanung zu berücksichtigen.

Ein erhebliches klinisches Problem stellen die osteoporosebedingten schleichenden Wirbelfrakturen dar. Sie verursachen starke Beschwerden und bei multisegmentalem Auftreten statisch bedeutsame Formveränderungen. Bis vor einigen Jahren waren hier nur symptomatische Maßnahmen in Form einer gewissen Ruhigstellung durch Bettruhe bzw. Korsettversorgung sowie medikamentöse Schmerzbekämpfung möglich. Angetrieben durch außerordentlich günstige Frühergebnisse hat die Kyphoplastie in den letzten Jahren das konservative Vorgehen zunehmend verdrängt. Auch die derzeit insoweit noch geltende Leitlinie der DVO (vor OP 3 Monate Wartezeit mit konservativer Behandlung) ist Gegenstand permanenter Diskussion, besonders auch wegen des häufig erheblichen Leidensdrucks der Patienten, welcher eine frühere Operation erzwingt. Bei Durchführung einer Kyphoplastie werden nach vorheriger MRT-Diagnose der Fraktur als Akutsinterung mittels minimalinvasivem Zugang unter Bildverstärkerkontrolle von dorsal die Pedikel punktiert und über so geschaffene Kanäle schnell härtende Knochenzementsubstanzen nach bestmöglicher Reposition des Wirbelkörpers in diesen eingebracht. Der Zement infiltriert aufgrund seiner primär flüssigkeitsnahen Konsistenz die Zwischenräume zwischen den rarefizierten Knochenbälkchen des Wirbelkörpers, wodurch die 
sinterungsbedingte Instabilität umgehend beseitigt ist mit entsprechendem subjektiven Ergebnis. Es gibt bisher nur kurz- und mittelfristige Ergebnisse, diese weisen aber bei niedriger Komplikationsrate überzeugende subjektive Vorteile aus (Becker und Ogon 2006, Felder-Puig et al. 2009, Komp et al. 2004). Abgewartet werden muss, ob sich durch die unphysiologische Versteifung eines Bewegungssegmentes nachteilige Spätergebnisse einstellen, z.B. in Form von Anschlussfrakturen der benachbarten Wirbelkörper. Zunächst befürchtete Probleme durch Austritt des Knochenzementes aus dem Wirbelkörper mit Beeinträchtigung der direkt benachbarten Gefäß - Nervenstrukturen haben sich durch Nutzung einer die Zementmasse bei Eingeben derselben lokalisierenden Ballonumhüllung weitgehend vermeiden lassen.

Im Bereich der Extremitäten sind Osteoporosefrakturen entsprechend den pathophysiologischen Gegebenheiten am ehesten metaphysär lokalisiert. An den rumpfnahen Gelenken (Hüftgelenk, Schultergelenk) werden die oft sowieso schon limitierten Konsolidierungsergebnisse noch weiter verschlechtert, sodass der Implantation von Kunstgelenken großer Raum gegeben ist. Da durch die Osteoporose allerdings die Kortikalis häufig ebenfalls in ihrer Konsistenz verändert ist, entstehen hier nicht selten Verankerungsprobleme, welche die Langzeitergebnisse der Prothetik beeinträchtigen und die Verwendung von Sondermodellen erzwingen. Frakturen in räumlicher Nähe der mittleren und distalen Extremitätengelenke müssen in aller Regel ebenfalls operativ behandelt werden, sei es, um mitbetroffene Gelenkanteile funktionsstabil zu versorgen, sei es, um für eine achsen- und zeitgerechte Knochenheilung zu sorgen. Der metaphysäre Substanzverlust führt mangels Abstützung der trabekulär strukturierten Fragmentenden zu op- pflichtigen Fehlstellungen und hohen Instabilitätsgraden, welche eine Osteosynthese auch da erzwingen, wo ansonsten konservative Maßnahmen ausreichend gewesen wären. Die Osteosynthesen solcher Frakturen sind technisch anspruchsvoll, da Verankerungsprobleme für das zur Verwendung kommende Implantat bestehen. Die zur Fixierung der nahezu ausschließlich genutzten Metallplatten notwendigen Schrauben finden angesichts der verminderten Knochensubstanz nur wenig Halt, sodass unkonventionelle Metallanordnungen (z.B. Doppelplattenosteosynthesen) und nach Op- ende externe, zusätzlich stabilisierende Verbände zur Anwendung kommen müssen um einer Materiallockerung vorzubeugen. 
Auch die Verwendung von stabilisierendem Knochenzement im Sinne einer Verbundosteosynthese hilft - wie bei der Kyphoplastie - die Primärstabilität zu erhöhen und den Schrauben eine festere Verankerung zu ermöglichen - eine Methodik, welche ansonsten bei Knochentumoren angewandt wird (Hofmann 1992, Pavlidis et al. 2002). Trotz zunächst einwandfreiem Op-Ergebnis verbleibt dann immer noch das Problem der Knochenheilung, da sich auch bei klinisch regelrechter Adaptation der Fragmente die im Bruchbereich kontaktierenden Knochenflächen als zu gering erweisen können.

\subsection{Ziel und Fragestellung}

Östrogen und Alendronat werden prophylaktisch und therapeutisch im Rahmen der Östrogenmangelbedingten Osteoporose angesichts ihrer bekannten positiven Effekte auf den Knochenstoffwechsel eingesetzt, sind aber - besonders auch wegen ihrer Nebenwirkungen - nicht unumstritten. Weitere Untersuchungen zur Eingrenzung von Vor - und Nachteilen sind daher sinnvoll.

In der vorliegenden Arbeit soll die Wirksamkeit einer Applikation von Östrogen und Alendronat während der Frakturheilung des osteoporotischen Knochens überprüft werden. Dazu wurde angesichts vorheriger methodischer Erfahrungen auf das Rattenmodell zurückgegriffen (Lill et al. 2002 a, Lill et al. 2002 b, Thompson et al. 1995). Ovarektomierte Ratten wurden mit entsprechenden Futtermittelzusätzen versorgt, um deren Wirkung auf die Heilung einer später im Bereich der metaphysären Tibia angelegten und mit Plattenosteosynthese versorgten Osteotomie zu überprüfen. Qualitative (Biegeversuch) und quantitative (Mikroradiographie) Untersuchungen des Frakturbereiches wurden durchgeführt, die Ergebnisse, insbesondere auch in ihrer Konsequenz zur Zahnmedizin, diskutiert. 


\section{Die folgenden Fragen sollten beantwortet werden:}

1) Sind die methodisch verwendeten Verfahren (Biegeversuch - Mikroradiographie) valide; bringen sie untereinander und mit den bestehenden klinischen Erfahrungen vergleichbare Ergebnisse?

2) Liefert das Rattenmodell in der verwendeten Form zuverlässig eine östrogenmangelbedingte Osteoporose?

3) Welcher der beiden Futtermittelzusätze ist wirkungsvoller; ergeben sich Hinweise für die Klinik in Bezug auf therapeutischen Nutzen der jeweiligen Substanz?

4) Wie wirken die Substanzen am Knochen?

5) Welchen Bezug der Ergebnisse gibt es zur Zahnmedizin? 


\section{Material und Methoden}

\subsection{In-Vivo-Versuche}

\section{Versuchstiere}

Zur Durchführung der Tierversuche lag eine Genehmigung der Bezirksregierung Braunschweig vor (AZ: 509.42502/01-53.03). Es wurden 48 weibliche, drei Monate alte, geschlechtsreife Sprague-Dawley-Ratten (SD - Ratten) verwendet, welche aus einer anerkannten Versuchstierzuchtanstalt stammten (Winkelmann, Borken). Das Gewicht der Ratten lag zwischen 200 und 250g. Die Tiere wurden in Standardkäfigen (Makrolon IV) gehalten. Raumbeleuchtung erfolgte von 6Uhr bis 18Uhr, die Raumtemperatur betrug $23^{\circ} \mathrm{C}$ bei $55 \%$ relativer Luftfeuchtigkeit. Als Basisversorgung erhielten die Tiere sojafreies Pellet-Futter und Wasser zur freien Verfügung. Auf methodenbedingt notwendige Zusatzstoffe im Futter wird unten eingegangen (2.1.3). Während der gesamten Versuchszeit befanden sich die Tiere in der Zentralen Tierexperimentellen Einheit (ZTE) des Universitätsklinikums Göttingen und wurden dort von der Versuchsleiterin, der Doktorandin sowie von ausgebildeten Tierpflegern und -ärzten überwacht.

\subsubsection{Ovarektomie}

$\mathrm{Zu}$ Versuchsbeginn wurden 36 Tiere ovarektomiert, um den erwünschten Hormonmangelzustand zu erreichen; 12 Tiere verblieben als Kontrollgruppe.

\section{OP - Beschreibung}

In Kombinationsnarkose Xylazin (Rompun ${ }^{\circledR}$, Fa. Bayer) / S-Ketamin (Ketanest $\mathrm{S} \circledast$, Fa. Pfizer Pharma) (3,5 v/v, $1 \mathrm{ml} / \mathrm{kg})$ wurde nach Rasur und Desinfektion der Haut eine paravertebrale Inzision zwischen Rippenbogen und Hinterläufen angelegt. Unter Abschieben der Muskulatur wurde das Peritoneum dargestellt und eröffnet. Die Tuba uterina wurde nach Präparation bds. ligiert, anschließend erfolgte die Absetzung der Ovarien. Der Wundverschluss erfolgte schichtweise unter Naht des Peritoneums und der Haut. Zusätzlich wurde jedem Tier ein Transponder in der Nackenregion subkutan 
implantiert (UNO MICRO-ID - System, ISO-Transponder $12 \mathrm{~mm}$; UNO-Roesvastataal BV, Zevenaar, Holland) um postoperativ eine exakte Identifikation der Tiere zu gewährleisten. Nach OP-Ende wurden die Tiere in ihre Käfige zurückgesetzt und nach Schema versorgt.

\subsubsection{Fütterung und Gruppierung}

Ergänzend zu der Basisversorgung mit sojafreien Pellets (Ssniff SM R/M, 10 mm Pellets; Ssniff Spezialitäten GmbH, Soest) war zur Bearbeitung der Thematik die Verabreichung von Futterzusatzstoffen notwendig. Daraus, sowie nach der unter 2.1.2 beschriebenen Ovarektomie, ergab sich zwangsläufig eine Gruppierung der Tiere. Eine solche wurde auch zur besseren Dokumentation der Ergebnisse durchgeführt und findet sich in der Ergebnisbeschreibung (3) wieder.

\section{Folgende Tiergruppen wurden gebildet:}

1. 12 Tiere (Transp. Nr.: 1-12); nicht ovarektomiert (INT); sojafreies Futter ohne Zusatz

2. 12 Tiere (Transp. Nr.: 13-24); ovarektomiert (OVX); sojafreies Futter ohne Zusatz

3. 12 Tiere (Transp. Nr.: 25-36); ovarektomiert (E); sojafreies Futter plus 17-ßEstradiol (25 mg/kg; Sigma Medical, Apeldoorn, Holland); 0.086 g/ Tag Östrogenaufnahme

4. 12 Tiere (Transp. Nr.: 37-48); ovarektomiert (AL); sojafreies Futter plus Alendronat (10 mg/kg, Merck \& Co, New Jersey, USA); 0,17mg/ Tag Alendronataufnahme

Die Gruppe 1 ist dabei als gesunde „hormonnormale“ Kontrollgruppe anzusehen, deren Frakturheilung als optimale, zu erreichende Größe angesehen wird, die Gruppe 2 als osteoporotische Kontrollgruppe ohne medikamentöse Therapie. Die von den Tieren aufgenommene Futtermenge wurde wöchentlich bestimmt, um eine geregelte 
Nahrungsaufnahme zu gewährleisten. Darüber hinaus wurden die Tiere im gleichen Zeitabstand gewogen, um Gewichtsschwankungen zu erfassen.

\subsubsection{Metaphysäre Osteotomie und Osteosynthese}

Zehn Wochen nach durchgeführter Ovarektomie besteht nachweislich ein Hormonmangelzustand mit Ausbildung einer Osteoporose. Zu diesem Zeitpunkt wurde die Osteotomie der Tibia durchgeführt.

\section{OP - Beschreibung}

In gleicher Kombinationsnarkose (2.1.2) wurde nach Rasur und Desinfektion der Rattenbeine die Tibia unter größtmöglicher Schonung der umgebenden Weichteile im proximalen Drittel freipräpariert. Von ventral wurde hier eine 5-Loch-Platte (XS 5705140, Stryker Trauma, Selzach, Schweiz) mit transversaler Biegung an den unverletzten Knochen angepasst und gelenknah, sowie diaphysär mit jeweils 2 Schrauben fixiert. Diese präliminare Fixation diente der Gewährleistung der korrekten Rotations- und Achsenverhältnisse nach Durchführung der Osteotomie. Nach Wiederentfernen der Platten erfolgte dann - zur Schonung der Weichteile mittels gepulstem Ultraschall (Piezosurgery ${ }^{\circledR}$, Mectron Medical Technology, Carasco, Italien) - die Osteotomie ca 5 mm distal des Kniegelenkes gelenkparallel. Nach Wiederanbringen der Platte mittels der vorgelegten Schraubenkanäle verblieb eine Osteotomiespaltbreite von ca. 0,5 mm. Die

Osteosynthese konnte als funktionsstabil bezeichnet werden. Zur Versorgung von Muskulatur und Haut wurde Vicryl 4.0 (Fa. Ethicon, Johnson \& Johnson, USA) verwandt.

Postoperativ erhielten die Tiere $2 \times$ tgl. über 3 Tage eine subkutane Schmerzmittelgabe (Perphenacin 5mg/kg KG sowie Carprofen $4 \mathrm{mg} / \mathrm{kg} \mathrm{KG}$ ), um die Normalisierung der Bewegungsabläufe zu optimieren. Die Wunden wurden regelmäßig überwacht - weitere medizinische Maßnahmen waren nicht erforderlich. 


\subsubsection{Zusätzliche Maßnahmen im Rahmen der Versuchszeit}

Um die Zahl der Versuchstiere möglichst gering zu halten, wurde versucht, die hier zur Diskussion stehenden Fragen am gleichen Tier mit weiteren methodischen Ansätzen zu bearbeiten. Das führte zu Maßnahmen, welche zwar die gleichen Versuchstiere betrafen, den hier beschriebenen Ablauf aber nicht beeinflussten und somit nur der Vollständigkeit halber erwähnt werden sollten.

1. Es wurden Osteotomien an beiden Tibiae simultan durchgeführt; die Vergleichsseite wurde zur Bestimmung der Genexpression im Kallus genutzt.

2. Während der Versuchszeit wurden Markersubstanzen gegeben, um die Knochenheilung sequentiell überprüfen zu können:

$\mathrm{XO}=$ Xylenol-Orange Tetranatriumsalz (Merck Best. Nr. 1.08677) 13.Tag nach Ost. Dosis: $90 \mathrm{mg} / \mathrm{kg} \mathrm{KG}$

$\mathrm{CG}=$ Calcein (Merck Best. Nr. 1.02315)

18.Tag nach Ost.

Dosis: $10 \mathrm{mg} / \mathrm{kg} \mathrm{KG}$

$\mathrm{AK}=$ Alizarinkomplexon (Merck Best. Nr. 1.01010)

24/26.Tag nach Ost.

Dosis: $30 \mathrm{mg} / \mathrm{kg} \mathrm{KG}$

$\mathrm{TC}=$ Tetracyclin $-\mathrm{HCl}$

30.Tag nach Ost.

Dosis: $25 \mathrm{mg} / \mathrm{kg} \mathrm{KG}$ 


\subsection{Versuchsende}

Die Versuchsdauer war auf 35 Tage festgelegt; zu diesem Zeitpunkt kann eine knöcherne Überbrückung des Osteotomiespaltes erwartet werden.

Die Versuchstiere wurden zum festgesetzten Zeitpunkt in tiefer $\mathrm{CO}^{2}$ - Narkose durch Dekapitation getötet. Bei den zur morphologischen Untersuchung vorgesehenen Tibiae wurde die zugehörige Fibula am proximalen Tibio - Fibulargelenk separiert. Die Metallteile wurden entfernt, die Präparate bei $-20^{\circ}$ bis zur weiteren Untersuchung gelagert.

\subsection{Knochenanalyse}

Zur Analyse von Qualität und Quantität der unter den oben beschriebenen Versuchsbedingungen abgelaufenen Knochenumbauvorgänge wurden biomechanische und mikroradiographische Untersuchungsverfahren verwendet.

\subsubsection{Biomechanische Untersuchung der metaphysären Tibia}

Ziel der biomechanischen Analyse war es, die Biegefestigkeit des verheilten Knochens mittels genormter Krafteinleitung in das Präparat unter den verschiedenen, zuvor experimentell erzeugten Bedingungen, zu überprüfen. Um die sich anschließenden mikroradiographischen Untersuchungen möglich zu machen, musste dabei die Integrität des Präparates gewährleistet bleiben. Somit musste die Krafteinleitung beendet werden, bevor es bei Verlassen des elastischen Beanspruchungsbereiches zur morphologischen Veränderung desselben durch iatrogene Frakturierung oder plastischen Verformung kam. Es galt also, den so skizzierten Punkt (Streckgrenze oder ,yield-load“) für die hier zur Verwendung kommenden Rattentibiae genau zu kennen und das Erreichen desselben durch möglichst nah vor ihm liegenden Versuchsabbruch zu vermeiden. Um dieses zu ermöglichen, wurde auf Voruntersuchungen zurückgegriffen, aus welchen die Maximalkraftwerte der Rattentibia unter verschiedenen Versuchsbedingungen (Norm, Osteoporose, verschiedene Fütterungsbedingungen) bekannt waren. Unter Berücksichtigung dieser Erfahrungswerte musste die Elastizitätsprüfung jeweils bei 60- 
$80 \mathrm{~N}$ beendet werden. Damit war eine optimale Prüfung der Biegefestigkeit des Knochens bei einem Sicherheitsspielraum von ca. $20 \%$ gewahrt.

Versuchsanordnung: Für die Elastizitätsprüfung wurde eine in Vorversuchen entwickelte und geeichte Zwick-Prüfmaschine mit einer rutschfesten Aluminium-Auflage für die Tibia genutzt (Abb. 2+3; Prüfmaschine und Auflage) (Stürmer et al. 2005).

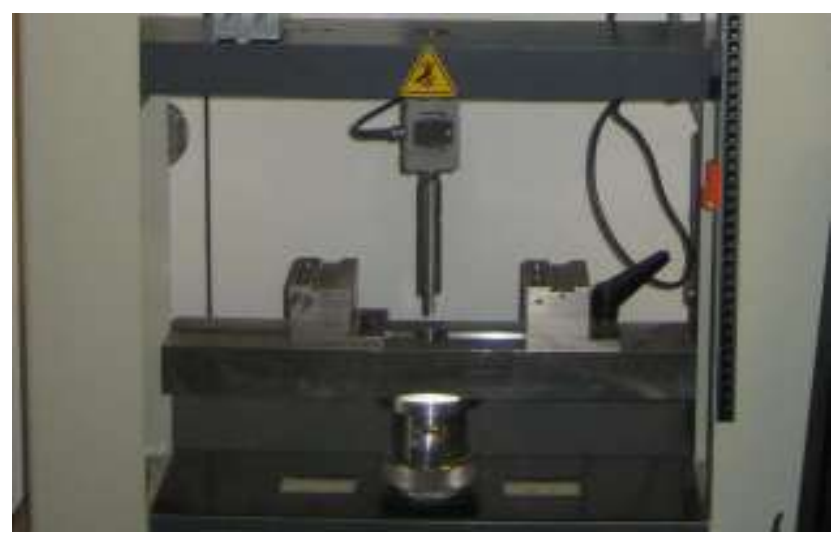

Abb. 2: Zwick-Prüfmaschine

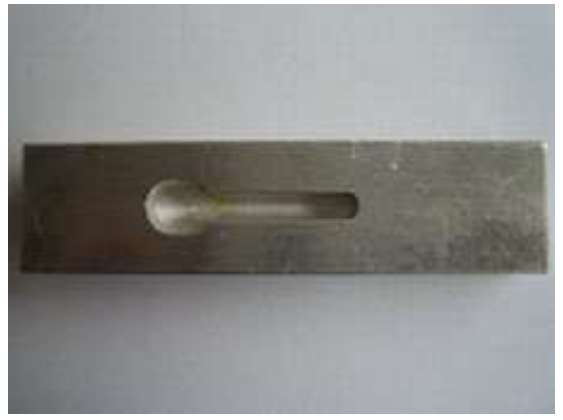

Abb. 3: Metallauflage mit Vertiefung zur Fixierung der Tibia

Nach Auftauen der Präparate und Separieren der Fibula am proximalen Tibio Fibulargelenk wurde die Tibia mit dem proximalen Ende auf der Aluminiumbasis der Maschine gelagert, wodurch die erforderliche Stabilität der Versuchsanordnung gewährleistet werden konnte. Das so geschaffene System wurde nunmehr einem Biegedruck ausgesetzt. Die so genannte Vorkraft wurde zunächst mechanisch bis zur Höhe von 1N appliziert; anschließend erfolgte ein Stop zur Systemüberprüfung, besonders des korrekten Druckpunktes. Bei somit abgesichert einwandfreien Versuchsbedingungen wurde die Krafteinleitung unter manueller Kontrolle fortgesetzt. 
Auf diese Weise konnte die Untersuchung individuell ohne das unerwünschte Verlassen des elastischen Belastungsbereiches abgeschlossen werden. Die anhand dieser Versuchsanordnung ermittelten und computerdokumentierten Kraftwerte wurden in Kurvenform dargestellt.

Aus diesen Kurven konnten für die einzelnen Tiergruppen Mittelwerte und Standardabweichungen der beiden versuchsrelevanten Parameter errechnet werden.

1. Elastizität: Sie bezeichnet das Mass der Steigung der im Einzelfall ermittelten Kurve; Die Steigung wiederum ist proportional zur Höhe der einwirkenden Biegekraft und gibt damit im Rahmen der Knochenheilung speziell Anhaltspunkte über die Elastizität des Kallus.

2. Streckgrenze: Sie bezeichnet den Punkt der maximalen Streckung eines Körpers, welche noch reversibel ist. Darüber hinausgehend verändert sich der Knochen plastisch; die folgende Dehnung ist irreversibel.

\subsubsection{Mikroradiographische Untersuchungen}

Die Mikroradiographie gibt Anhaltspunkte für das lokal existente Ausmaß der Knochensubstanz. Ortsständige und neugebildete Anteile können durch Graustufenunterschiede erfasst und differenziert werden. Die so bestimmte Substanzmenge ist damit Ausdruck der Reaktivität des Organismus, hier in Bezug auf die Heilung der Fraktur, unter den jeweiligen experimentellen Bedingungen. Da mit Hilfe der Mikroradiographie Substanzmengen und in den Biegeversuchen deren Stabilität analysiert werden können, ergibt sich somit ein optimaler Synergismus in Bezug auf die Potenz des Organismus, möglichst ideale Stabilitätsverhältnisse nach einer Verletzung wiederherzustellen.

\subsubsection{Herstellung der Präparate}

Nach Abgeschlossener Elastizitätsprüfung wurden die Tibiae für die mikroradiographische Untersuchung vorbereitet. Dazu wurden sie in aufsteigender Alkoholreihe (40\%, 70\%, 80\% und 100\% Ethanol für jeweils 7 Tage) entfettet und 
entwässert. Die Einbettung erfolgte dann über 21 Tage in einer Mischung aus $1000 \mathrm{ml}$ Methylmethacrylat, 200ml Dibutylphthalat und 29g Benzoylperoxid (Abb. 4).

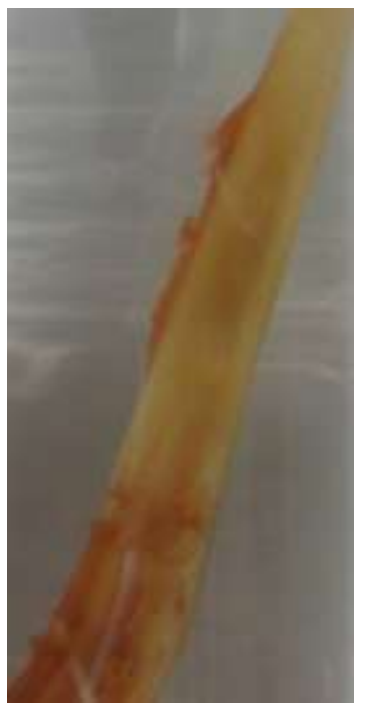

Abb. 4: In Methylmethacrylat eingebettete Rattentibia

Die so hergestellten Methylmetacrylatblöcke mit integriertem Knochen wurden mit einer diamantierten Säge in $100 \mu \mathrm{m}(+/-20 \mu \mathrm{m})$ dicke Präparate geschnitten. Die Schnittrichtung lag sagittal und senkrecht zur Plattenebene, sodass die Knochenstrukturen anschließend in ap-Richtung analysiert werden konnten (Abb. 5).

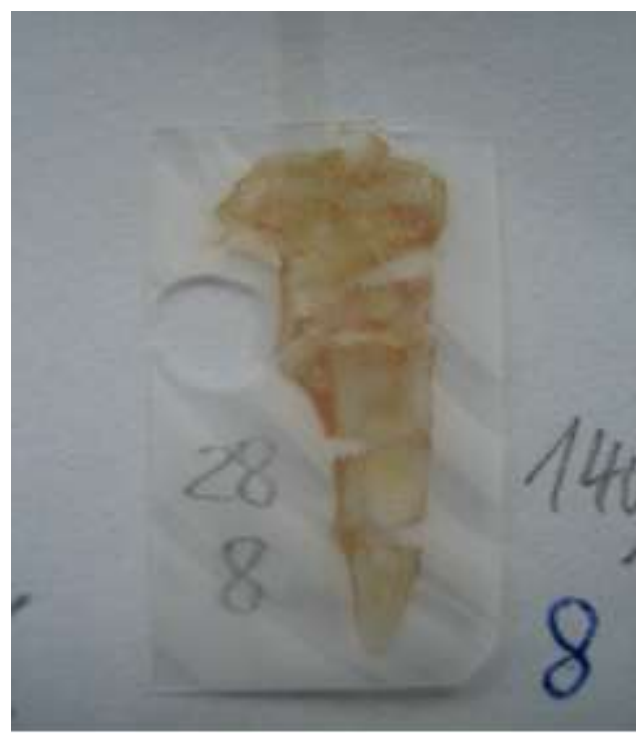

Abb. 5: Schnittpräparat eines Tibiaknochens aus dem Methylmethacrylatblock 
Von den so entstandenen Längsschnitten wurden die 3 zentralen zur Analyse vorgesehen, um den wesentlichen Teil der relevanten osteotomienahen Knochenanteile auch sicher zu erfassen.

\subsubsection{Herstellung der Mikroradiographien}

Die 3 Schnitte wurden nunmehr einer Röntgenuntersuchung unterzogen (Faxitron, Modell-Nr.: 43855A, Hewlett Packard, USA). Die Belichtung erfolgte dabei mit 10kv und $0,3 \mathrm{~mA}$; die Belichtungszeit betrug jeweils 3 Minuten. Weiterhin erfolgten Entwicklung und Fixation des Filmes sowie Trocknung unter staubfreien Verhältnissen. Die so erstellten Röntgenfilme wurden entsprechend den oben angegebenen Gruppeneinteilungen markiert und bis zur Auswertung dunkel gelagert.

\subsubsection{Auswertung der Mikroradiographien}

Für die computergestützte quantitative Auswertung der Mikroradiographien standen ein Makroskop (Leica MZ 7, Bensheim) mit aufgesetzter Digitalkamera (Leica DC 200, Bensheim) sowie ein Computer (Intel Pentium 4, 2,6 GHz) mit entsprechender Software (Leica Quantimed QWin 2003, Bensheim) zur Verfügung. Die einzelnen Belichtungsmöglichkeiten des Makroskopes (Kaltlichtquelle Leica KL 1500 LCD, Bensheim) waren durch Vorversuche bereits festgelegt; es wurden Halogenlampentemperaturen von ca. $3000 \mathrm{~K}$ benutzt. Die relevanten Knochenareale wurden nach Platzierung des Präparates mit einem Touch-Pet mit dazugehörigem Pen umfahren; die ermittelten Werte wurden dem Computer zur Auswertung übermittelt. Der Computer bestimmte aus den mittels Pen vorgegebenen Werten gemittelte Ergebnisse, welche unten (3.2) in 14 Abbildungen dargestellt werden. Die Analyse der Schnitte erfolgte verblindet in Bezug auf die Versuchsgruppen. Unter Berücksichtigung der lokalen Situationen „Kortikalis“, „Trabekel“ und „Kallus“ wurden die Parameter „Dicke“ und „Dichte“ bestimmt.

Um benutzerspezifische Fehler bei Durchführung der Untersuchungen zu minimieren, erfolgte vor Beginn der eigentlichen Auswertung eine Eichung an 5 aufeinanderfolgenden Tagen. Dabei wurden durch den Untersucher die oben 
angegebenen Messparameter an 5 Schnitten erhoben; Differenzen mussten unter 10\% liegen.

\subsubsection{Statistische Auswertung}

Die statistischen Berechnungen wurden mit Hilfe des Programmes „Graph Pad Prism“ in der Version 4.00 (Graph Pad Software Inc., San Diego, USA) durchgeführt. Die für die einzelnen Gruppen und Parameter ermittelten Versuchsergebnisse wurden mit Hilfe des tTestes bei einem $\mathrm{p}$-Wert von $\alpha \leq 0,05$ analysiert. 


\section{Ergebnisse}

Die nachfolgend dargestellten Ergebnisse beziehen sich nur auf die Fälle mit regelhaftem Heilverlauf. Ausgeschlossen wurden die Tiere mit Infektionen und mechanischen Komplikationen im Sinne eines Implantatversagens. Nur durch dieses Vorgehen konnte gewährleistet werden, dass die hier zu untersuchenden Einflussgrößen, Östrogen bzw. Alendronat, auch tatsächlich vergleichbaren experimentellen Bedingungen unterlagen.

Unter diesen Voraussetzungen konnten einer Analyse zugeführt werden:

Gruppe 1 (INT) : 20 Schnitte

Gruppe 2 (OVX) : 19 Schnitte

Gruppe 3 (E) : 30 Schnitte

Gruppe 4 (AL) : 26 Schnitte

Die Zahl der vergleichbaren Präparate lag damit in einem Bereich, welcher eine aussagekräftige Ergebnismitteilung auch unter statistischen Bedingungen erlaubte.

\subsection{Biomechanische Untersuchung}

Entsprechend den in Abschnitt 2.3.1 erläuterten Vorgaben wurden die aus den Biegeversuchen resultierenden Kurven in Bezug auf die versuchsrelevanten Parameter „Steigung“ (Abb.6) und „Streckgrenze“ (Abb.7) analysiert. Die Ergebnisse werden in Balkendiagrammen dargestellt und enthalten die jeweiligen gruppenspezifischen Mittelwerte. Oberhalb und unterhalb der Balkengrenzen sind die Standardabweichungen angegeben, welche im Text passend zu den jeweiligen Mittelwerten genau ausgeführt werden.

Die Unterschiede zwischen den einzelnen Gruppen wurden als signifikant angegeben, wenn der errechnete Wert $\mathrm{p} \leq 0,05$ war. 


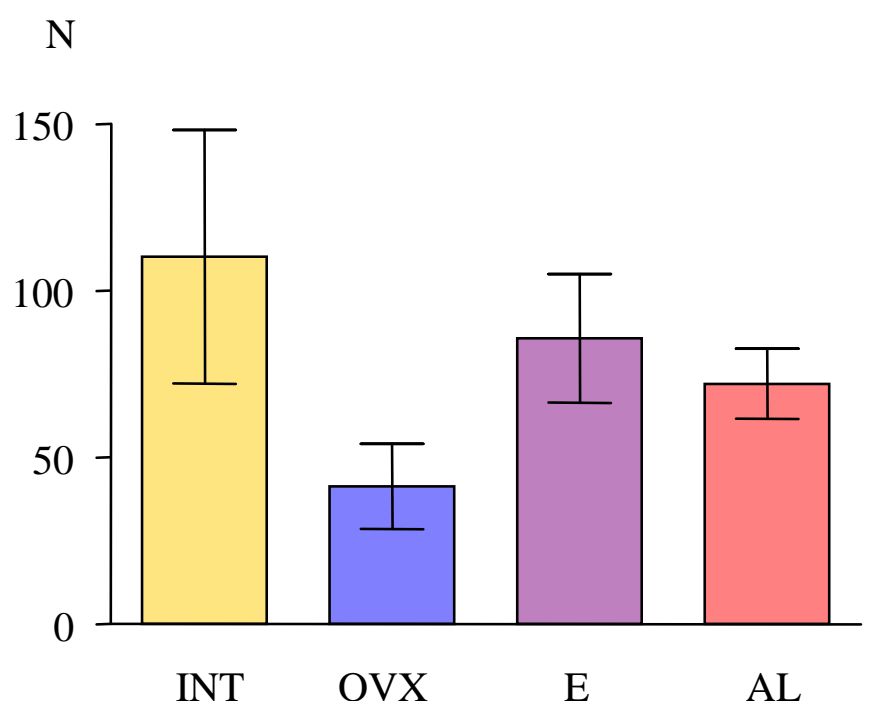

Abb. 6: Elastizitätswerte der Tibiae bei biomechanischer Untersuchung

Es konnten keine Signifikanzen mit einem Wert von $\mathrm{p} \leq 0,05$ errechnet werden.

Die Mittelwerte ergaben sich wie folgt: INT: 110,2 \pm 38,4; OVX: 41,28 \pm 12,74; E: 85,72 $\pm 19,28$ und AL: $72,07 \pm 10,46$.

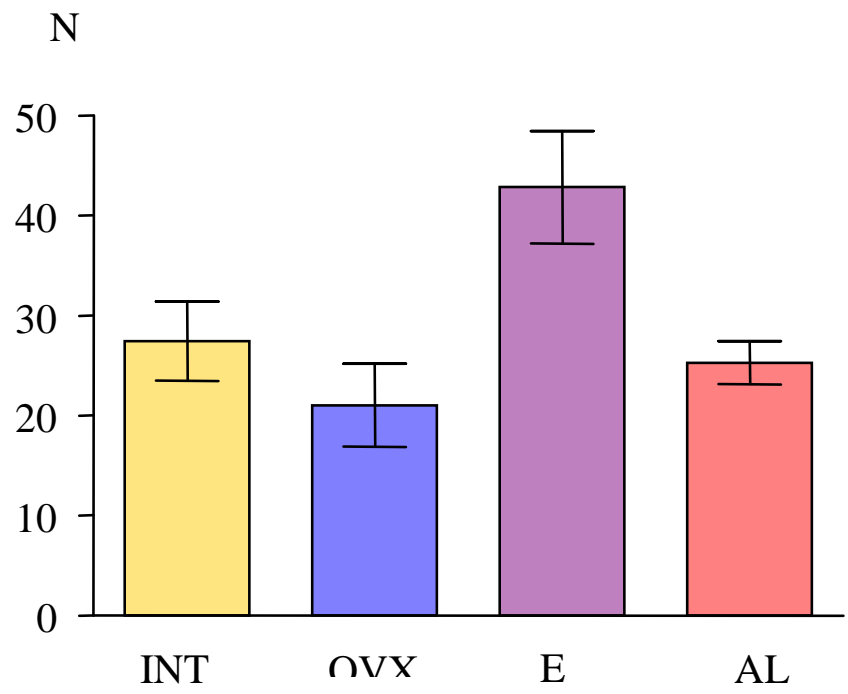

Abb. 7: Streckgrenze der Tibiae bei biomechanischer Untersuchung (keine plastische Verformung ersichtlich)

Es konnten Signifikanzen mit Werten unter $\mathrm{p}=0,05$ zwischen OVX und E und zwischen E und AL berechnet werden. 
Die Mittelwerte ergaben sich wie folgt: INT: 27,44 \pm 3,968; OVX: 21,04 \pm 4,157; E: 42,85 $\pm 5,61 ;$ AL: $25,28 \pm 2,133$.

Die benutzten Futtermittelzusätze Östrogen und Alendronat führten zu einer Verbesserung der Bruchresistenz mit deutlichen Vorteilen für Estradiol. Beide versuchsrelevanten Parameter („Elastizität“ und „Streckgrenze“) zeigten nahezu deckungsgleiches Verhalten. Die Standardabweichungen waren in der intakten Gruppe am höchsten.

\subsection{Ergebnisse der Mikroradiographien}

Die Ergebnisdarstellung erfolgt anhand von Mittelwertabbildungen, auf denen oberhalb und unterhalb der Balkenenden die Standardabweichungen verzeichnet sind. Diese sind im Text unterhalb der Diagramme passend $\mathrm{zu}$ den jeweiligen Mittelwerten genau ausgeführt.

Die Unterschiede zwischen den einzelnen Gruppen werden als signifikant angegeben, wenn der errechnete Wert $\mathrm{p} \leq 0,05$ ist.

\subsubsection{Kallusdichte}

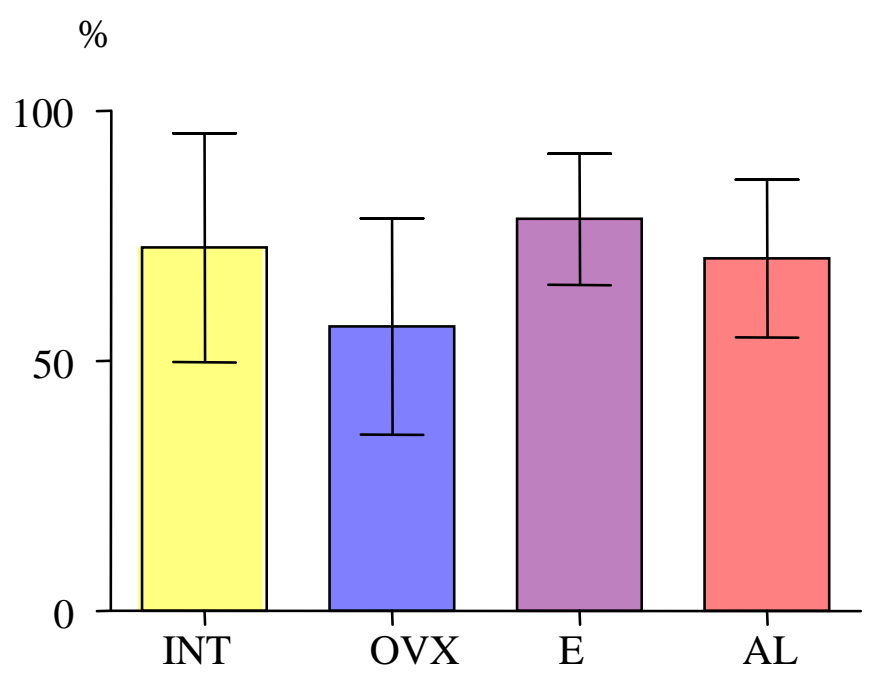

Abb. 8: Quantitativ, mittels Mikroradiographie, ausgewertete Kallusdichte (ventral) 
Es konnten Signifikanzen mit Werten unter $\mathrm{p}=0,05$ zwischen OVX und allen 3 anderen Gruppen (INT, E und AL) errechnet werden.

Den höchsten Mittelwert wies mit 78,36\% $( \pm 13,14)$ die E-Gruppe auf, er überstieg sogar denjenigen der INT-Gruppe mit 72,50\% $( \pm 22,85)$. Für die OVX-Gruppe $(56,71 \% \pm 21,57)$ als auch für die Alendronat-Gruppe (AL: 70,42\% $\pm 15,75$ ) ergaben sich etwas niedrigere Werte.

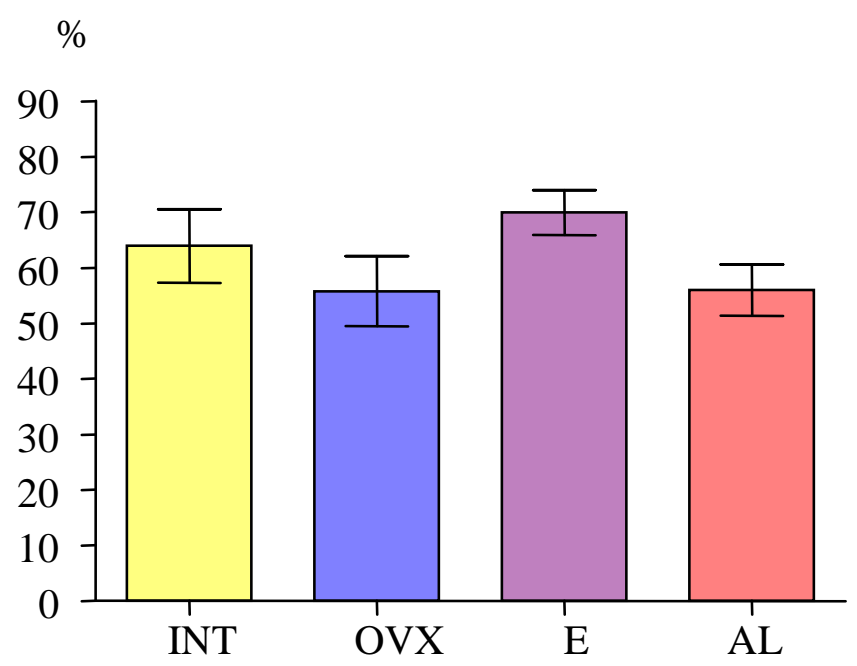

\section{Abb. 9: Quantitativ, mittels Mikroradiographie, ausgewertete Kallusdichte (dorsal)}

Es konnten Signifikanzen mit Werten unter $\mathrm{p}=0,05$ zwischen $\mathrm{E}$ und $\mathrm{AL}$ errechnet werden. Die Werte wiesen die gleiche Gruppenverteilung auf wie in Abb.8; auch hier zeigte die E-Gruppe die höchsten Werte $(69,91 \% \pm 4,02)$ vor der INT-Gruppe mit $63,91 \%,( \pm 6,653)$, der AL-Gruppe mit 55,95\% $( \pm 4,613)$ und der OVX-Gruppe mit 55,74\% $( \pm 6,299)$ - also fast gleich hohen Werten wie in der E-Gruppe. 


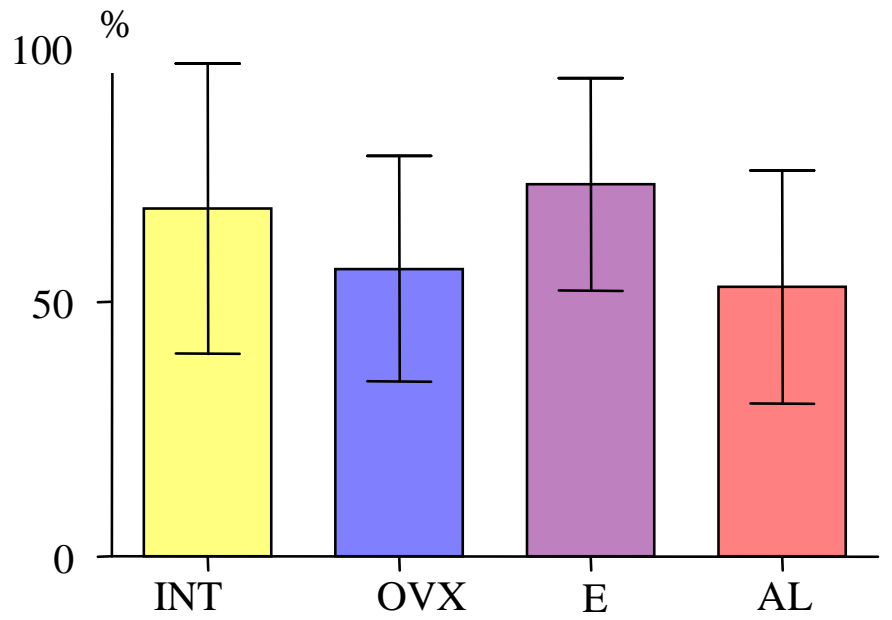

Abb. 10: Quantitativ, mittels Mikroradiographie, ausgewertete Kallusdichte (endostal)

Es konnten Signifikanzen mit Werten unter $\mathrm{p}=0,05$ zwischen $\mathrm{E}$ und AL und OVX errechnet werden, sowie zwischen INT und AL.

Wiederum höchster Dichtewert $(73.12 \% \pm 20,87)$ für die E-Gruppe; die Effektivität der Estradiolgabe ließ sich danach, wie auch bei den anderen beiden Kallusdichteuntersuchungen verifizieren; besonders deutlich war der Unterschied zu den OVX $(56,48 \% \pm 22,14)$ und AL-Gruppen $(52,93 \% \pm 22,89)$. Der Wert der INT-Gruppe lag bei $68,28 \% \pm 28,47$. 


\subsubsection{Kallusgröße}

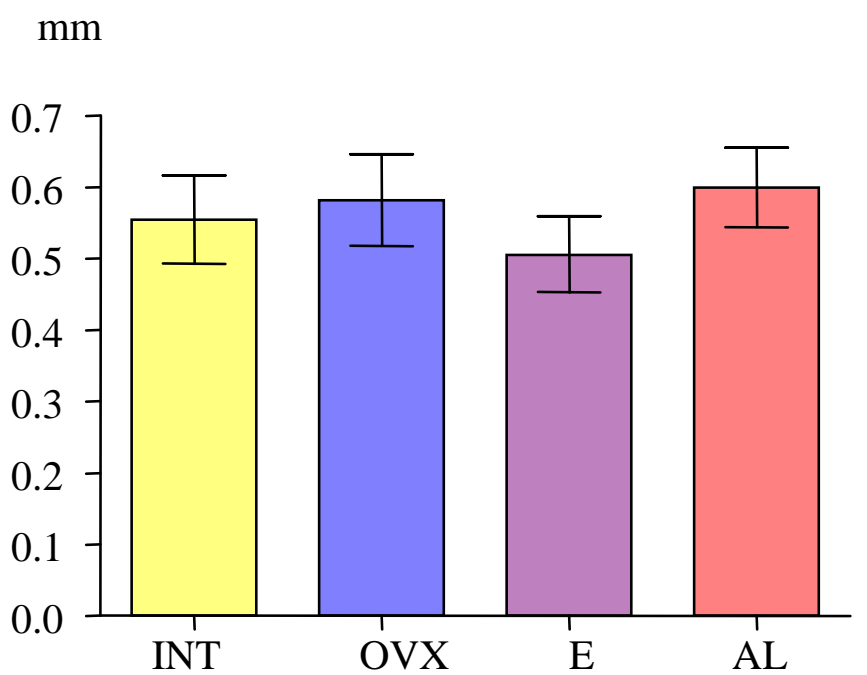

Abb. 11: Quantitativ, mittels Mikroradiographie, ausgewertete Kallusdicke (ventral)

Es konnten keine Signifikanzen mit einem Wert von $\mathrm{p} \leq 0,05$ errechnet werden.

Die Werte der Kallusdicke ventral lagen zwischen 0,51mm $\pm 0,05$ (E-Gruppe).und 0,60mm $\pm 0,06$ (AL-Gruppe) und waren in allen Gruppen ähnlich hoch (INT: 0,55mm $\pm 0,06$ und OVX: 0,58mm $\pm 0,06$ ); damit bestand in Bezug auf die Kallusdicke kein bedeutsamer Medikamenteneinfluss. Ebenso wenig war ein osteoporosebedingtes Defizit festzustellen.

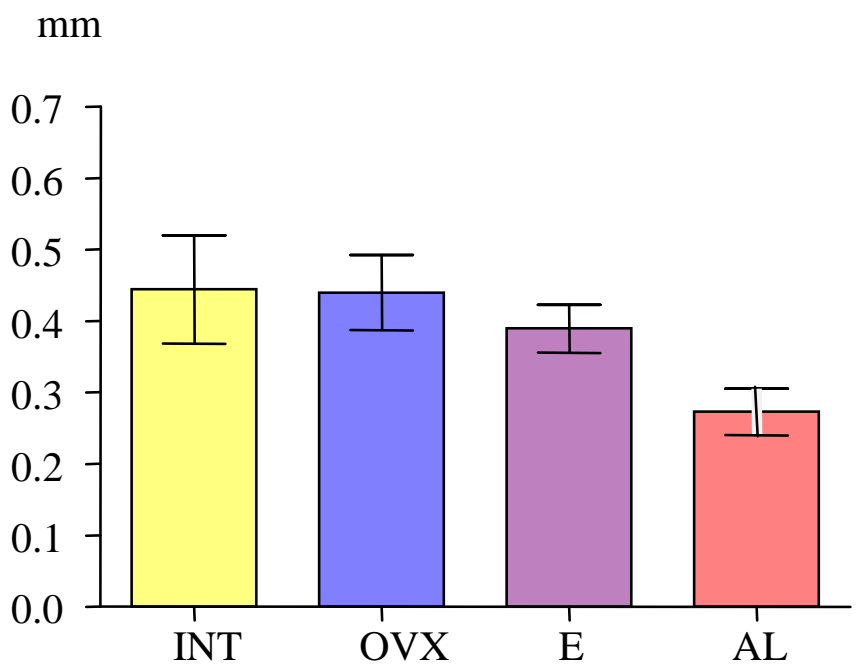

Abb. 12: Quantitativ, mittels Mikroradiographie, ausgewertete Kallusdicke (dorsal) 
Es konnten Signifikanzen mit Werten unter $\mathrm{p}=0,05$ zwischen AL und allen anderen 3 Gruppen (INT, OVX und E) errechnet werden.

Dorsalseitig zeigte sich kein positiver Einfluss auf die Dicke des Kallus, weder bei Estradiol $(0,39 \mathrm{~mm} \pm 0,03)$, noch bei Alendronatgaben $(0,27 \mathrm{~mm} \pm 0,03)$. Auch hier zeigte sich kein osteoporosebedingtes Defizit der OVX-Gruppe mit $0,44 \mathrm{~mm}( \pm 0,05)$ gegenüber der INT-Gruppe mit 0,44mm $( \pm 0,05)$.

\subsubsection{Trabekelsystem}

Durch die Untersuchungen am Trabekelwerk können Aussagen zum metaphysär intraossalen Umbau gemacht werden; es werden Werte in Bezug auf einzelne Trabekel sowie auf deren Kreuzungspunkte dargestellt.

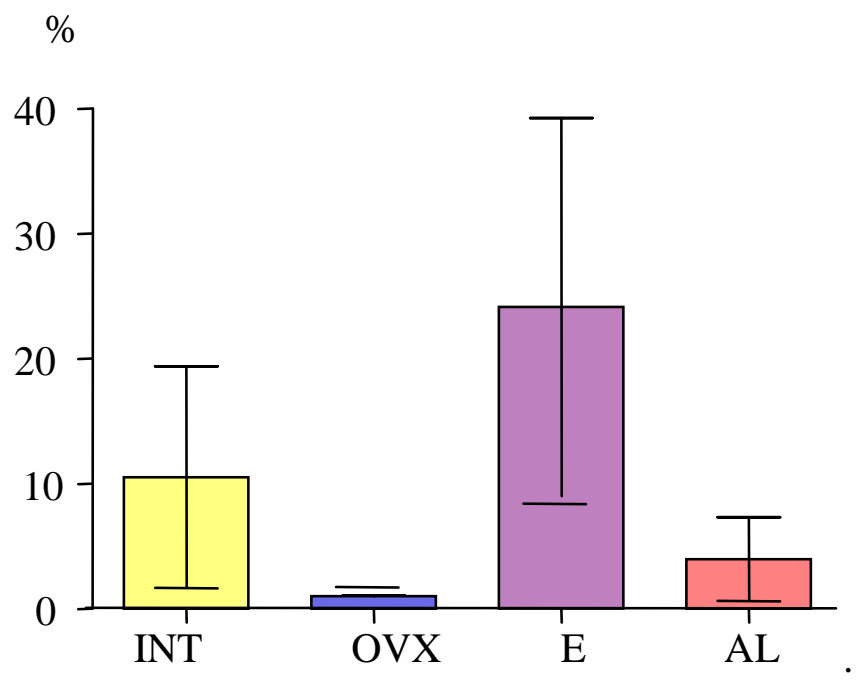

Abb. 13: Quantitativ, mittels Mikroradiographie, ausgewertete Trabekeldichte (distal)

Es konnten Signifikanzen mit Werten unter p=0,05 zwischen OVX und INT als auch E errechnet werden, außerdem zwischen E und AL.

Im Vergleich $\mathrm{zu}$ allen anderen Untersuchungen war hier der positive Einfluss von Estradiol auf die untersuchte Knochenstruktur am größten; mit $24,13 \%( \pm 34,09)$ Trabekelanteil am Gesamtquerschnitt lag der errechnete Wert besonders deutlich über dem der OVX-Gruppe mit 1,01\% $( \pm 0,14)$. Der Östrogenmagel hatte damit im trabekulären Bereich eine besonders starke Substanzreduktion zur Folge, welche durch Estradiolgaben im Vergleich zur INT-Gruppe mit 10,53\% $( \pm 18,9)$ mehr als ausgeglichen 
wurde; auch gegenüber der AL-Gruppe mit 3,99\% $( \pm 8,3)$ ergaben sich erhebliche Vorteile, Alendronat zeigte dementsprechend nur einen leicht positiven Einfluss auf die intraossale metaphysäre Knochenneubildung.

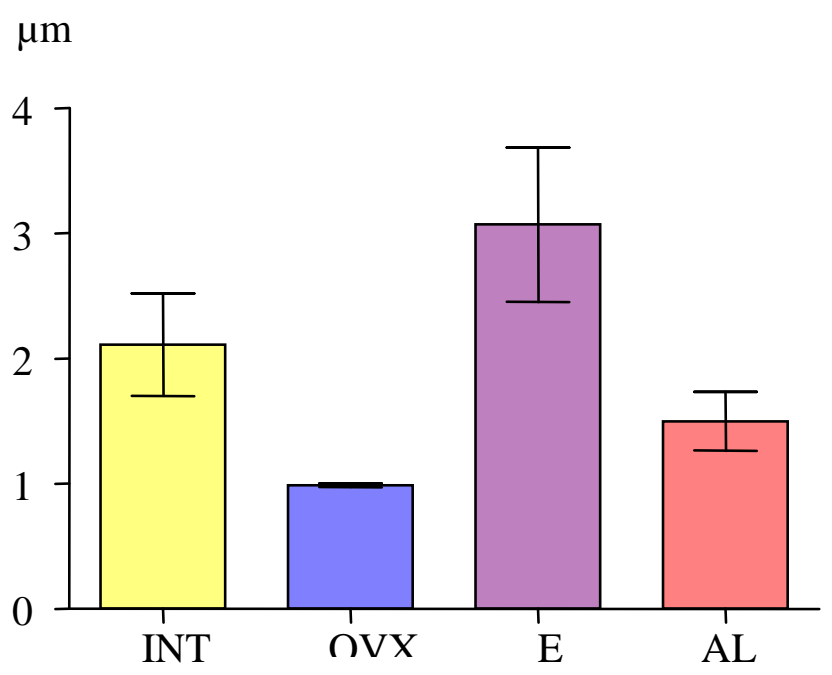

Abb. 14: Quantitativ, mittels Mikroradiographie, ausgewertete mittlere Trabekeldicke

Es konnten Signifikanzen mit Werten unter $\mathrm{p}=0,05$ zwischen $\mathrm{E}$ und $\mathrm{AL}$ als auch OVX errechnet werden, sowie zwischen INT und OVX.

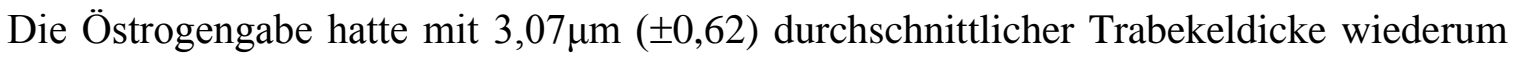

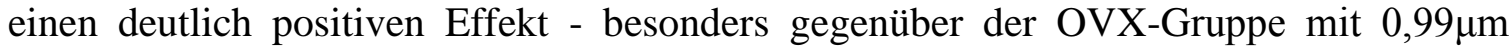
$( \pm 0,016)$. Der E-Wert lag auch über dem der INT-Gruppe $(2,11 \mu \mathrm{m} \pm 0,4)$, was die

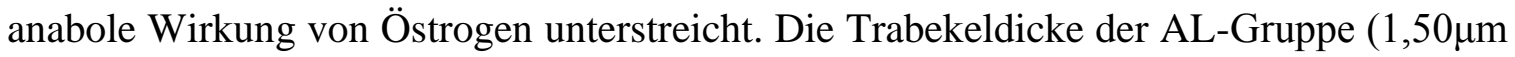
$\pm 0,24)$ liegt zwischen OVX und INT. 


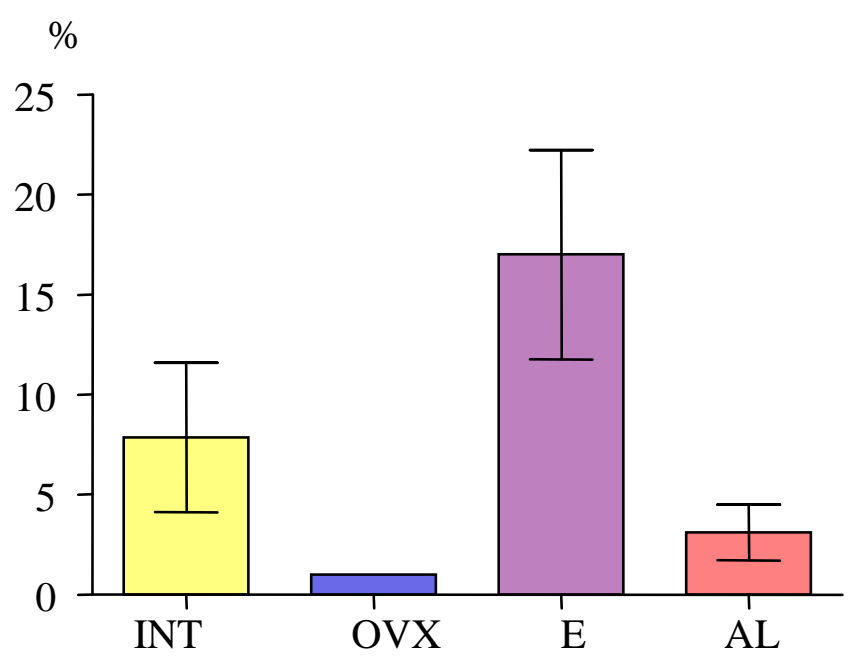

Abb. 15: Quantitativ, mittels Mikroradiographie, ausgewertete Dichte der Trabekelkreuzungen

Es konnten Signifikanzen mit Werten unter $\mathrm{p}=0,05$ zwischen E und AL, als auch OVX errechnet werden.

Auch die Dichtewerte der Trabekelkreuzungen waren bei der E-Gruppe mit 17,01\% ( \pm 5,24) im Vergleich zu allen anderen Gruppen am höchsten, überstiegen also auch hier die Werte der INT-Gruppe mit 7,86\% $( \pm 3,73)$; in der OVX-Gruppe waren die Werte ausserordentlich gering $(1,00 \% \pm 0,0)$ als Zeichen eines erheblich negativen Einflusses durch den Hormonmangel; Alendronatgaben $(3,11 \% \pm 1,4)$ waren nahezu wirkungslos.

\subsubsection{Kortikalis}

Die Kortikalis stellt im Vergleich mit den bereits untersuchten Vergleichsstrukturen „Kallus“ und „Trabekelsystem“ aufgrund der hier herrschenden lokalen Durchblutungsverhältnisse am wenigsten aktiven Teil des Gesamtsystems dar. Während mit den Untersuchungen am Kallus ausschließlich neugebildetes Knochengewebe und mit denen am Trabekelsystem Mischgewebe aus ortsständigem und neuem Gewebe erfasst wird, werden hier im wesentlichen ortsständige Anteile mit geringerem periostalem und endostalem Anbau gesehen. 


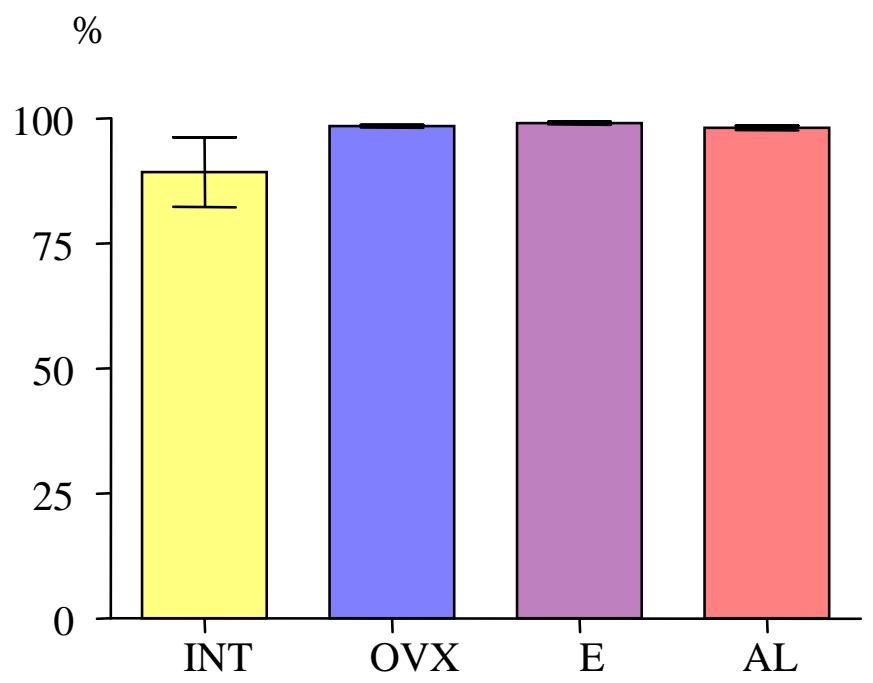

Abb. 16: Quantitativ, mittels Mikroradiographie, ausgewertete Kortikalisdichte ventral

Es konnten keine Signifikanzen mit einem Wert von $\mathrm{p} \leq 0,05$ errechnet werden.

Die Werte der einzelnen Gruppen zeigen kaum Unterschiede mit dem besten Wert für die E-Gruppe mit 99,13\% ( $\pm 0,23)$. Die hormonbedingte Osteoporose hatte im Bereich der Kortikalis keine negativen Auswirkungen. Die Werte für die übrigen Gruppen waren INT: 89,28\% $( \pm 6,9)$; OVX: 98,46\% $( \pm 0,29)$ und AL: 98,11\% $( \pm 0,4)$.

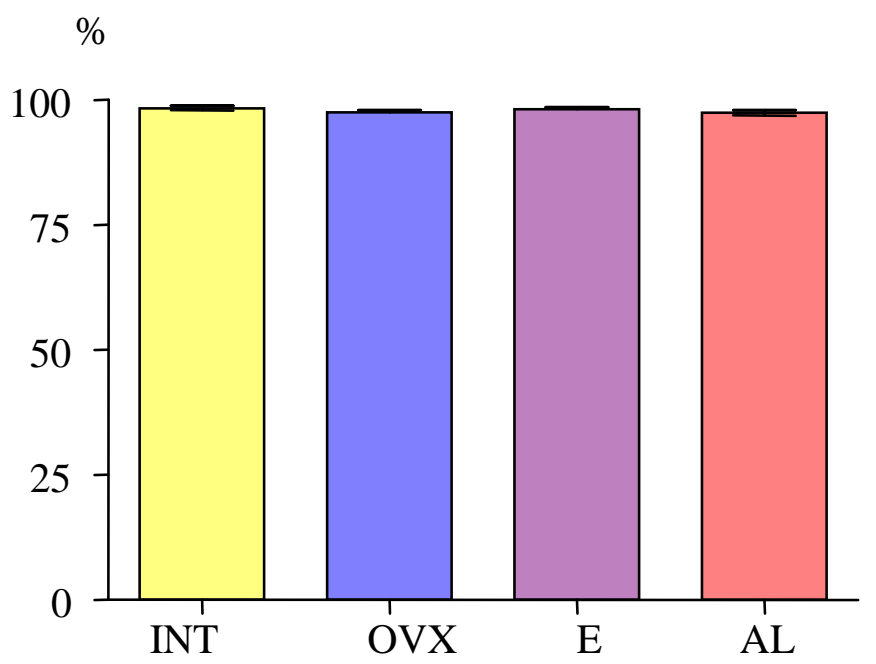

Abb. 17: Quantitativ, mittels Mikroradiographie, ausgewertete Kortikalisdichte dorsal 
Es konnten keine Signifikanzen mit einem Wert von $\mathrm{p} \leq 0,05$ errechnet werden.

Wiederum war die Kortikalisdichte distal dorsal in allen Gruppen sehr hoch, mit nur gering differierenden Werten. Die Gruppenwerte betrugen: INT: $98,33 \%( \pm 0,46)$; OVX: 97,42\% ( $\pm 0,46)$; E: $98,14 \%( \pm 0,44)$; AL: 97,41\% ( $\pm 0,56)$. Insgesamt bestand auch kein wesentlicher Unterschied zu den Dichtewerten im ventralen Kortikalisbereich (Abbildung $18)$.

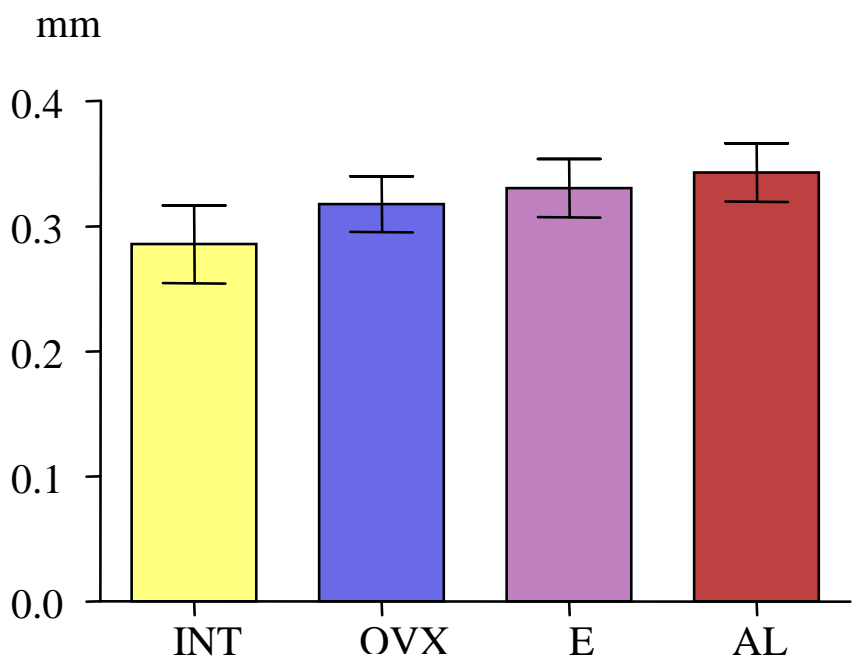

Abb. 18: Quantitativ, mittels Mikroradiographie, ausgewertete Kortikalisdicke ventral

Es konnten keine Signifikanzen mit einem Wert von $\mathrm{p} \leq 0,05$ errechnet werden.

Die Kortikalisdickewerte waren relativ einheitlich; ein relevanter Einfluss der Futtermittelzugaben war nicht zu erkennen: E lag bei $0,33 \mathrm{~mm}( \pm 0,11)$, AL bei $0,34 \mathrm{~mm}$ $( \pm 0,02)$; ein osteoporosebedingter Knochenverlust (OVX: 0,32mm $\pm 0,02)$ war nicht auszumachen. Die INT-Gruppe wies mit 0,29mm $( \pm 0,03)$ den geringsten Wert auf. 
$\mathrm{mm}$

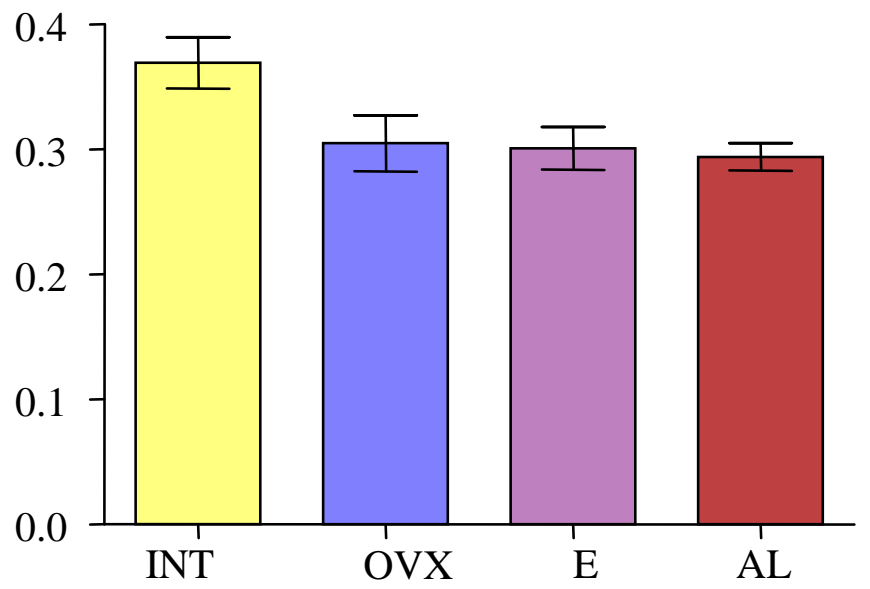

Abb. 19: Quantitativ, mittels Mikroradiographie, ausgewertete Kortikalisdicke dorsal

Es konnten Signifikanzen mit Werten unter $\mathrm{p}=0,05$ zwischen INT und E, als auch AL errechnet werden.

Gegenüber der INT-Gruppe mit $0,37 \mathrm{~mm}( \pm 0,02)$ war eine durch Futtermittelgabe beeinflussbare Ausdünnung des Knochens zu erkennen - insoweit differieren die Werte zu denen der im ventralen Kortikalisbereich erhobenen; Unterschiede zwischen der EGruppe mit 0,30mm $( \pm 0,017)$, der AL-Gruppe mit 0,29mm $( \pm 0,01)$ und der OVX-Gruppe mit $0,30 \mathrm{~mm}( \pm 0,02)$ gab es nicht. 


\subsection{Ergebniszusammenfassung}

Aus den oben (3.1. und 3.2.) dargestellten qualitativen und quantitativen Untersuchungsergebnissen lassen sich zusammenfassend folgende Schlüsse ziehen:

1. Die beiden verwendeten Untersuchungsmethoden lieferten übereinstimmende Ergebnisse und lassen damit eine als valide zu bezeichnende Beschreibung der Knochenheilungsabläufe unter den hier gewählten experimentellen Bedingungen zu.

2. Die Ovarektomie hat bei der Ratte infolge des durch sie bedingten Hormonmangelzustandes eine deutliche Minderung der Knochensubstanz zu Folge.

3. Die negativen Auswirkungen der Osteoporose lassen sich medikamentös beeinflussen.

4. Östrogengaben zeigen gegenüber Alendronatgaben deutlich bessere Effekte.

5. Die positiven Einflüsse beziehen sich insbesondere auf die Knochendichte, weniger auf die Knochendicke.

6. Positiv beeinflusst werden die Vorgänge durch Östrogen und Alendronat im Bereich des Kallusgewebes sowie diejenigen am Trabekelsystem - nicht hingegen an der Kortikalis 


\section{Diskussion}

\subsection{Die osteoporotische Fraktur als medizinisches und sozio- ökonomisches Problem}

Angesichts der demographischen Entwicklung der Bevölkerung werden Frakturen des alten Menschen zu einem medizinischen und gesellschaftlichen Problem. Es erwächst hieraus im Zuge der Überalterung der Bevölkerung eine zunehmende sozioökonomische Belastung (Scheidt-Nave 2001). Frauen sind angesichts ihrer höheren Lebenserwartung häufiger betroffen als Männer.

Die Ursache für das im Alter erhöhte Frakturrisiko liegt allerdings im Wesentlichen in der Entwicklung einer durch hormonelle Defizite hervorgerufenen Osteoporose der Frau. Die physiologische Reduktion des Östrogenspiegels in der Menopause hat eine altersabhängige Verminderung der Knochendichte zur Folge, welche bei Vorliegen eines entsprechenden Risikoprofils zum Auftreten osteoporotischer Frakturen führen kann. So liegt das Risiko einer fünfzigjährigen Frau, eine osteoporotische Fraktur aufgrund eines Östrogenmangels zu erleiden bei 40\% (Resch 2004). Vorwiegend metaphysäre Skelettabschnitte sind betroffen (Curtis et al. 2005). Klinisch bedeutungsvoll ist weiterhin, dass bedingt durch die verminderte Knochenqualität der Heilungsprozess nach Eintreten einer Fraktur verzögert ist (Augat et al. 2005, Barrios et al. 1993, Hao et al. 2007, Mc Cann et al. 2008, Nikolaou et al. 2009).

Aus therapeutischer Sicht liegt es nahe, Frakturinzidenz und -heilung durch medikamentöse Substitution $\mathrm{zu}$ beeinflussen. Östrogengaben empfehlen sich dabei nach den derzeitigen Erkenntnissen ebenso wie Bisphosphonate. Beide Substanzen sind in der Lage, die Knochenstruktur zu verstärken und damit zumindest theoretisch das Frakturgeschehen positiv zu beeinflussen. Eine Vielzahl klinischer Therapieempfehlungen wurde demzufolge gegeben. Ein konsequenter Einsatz wird jedoch durch die erheblichen Nebenwirkungen der Präparate noch eingeengt, sodass hier nach wie vor erhebliche Unsicherheiten bestehen. Dementsprechend ist es notwendig, mittels weiterer klinischer und experimenteller Studien Aufschluss zu gewinnen.

\subsection{Das Tiermodell}

Ein Absinken der Östrogenkonzentration infolge der Menopause spielt bei der Entstehung der postmenopausalen Osteoporose eine bedeutende Rolle, allerdings existiert mit Ausnahme weniger Primaten keine Tierart, bei der es physiologischerweise zu einer Menopause kommt. 
Somit bleibt in der Forschung oftmals nur die Möglichkeit eine solche mittels Ovarektomie zu induzieren. Folglich ist kein Tiermodell in der Lage, dem Verlust der ovariellen Funktion der Frau gänzlich zu entsprechen. Während die Menopause und der damit verbundene Östrogenverlust bei der Frau ein schleichender Prozess ist, bewirkt eine Ovarektomie einen abrupten Abfall des Östrogenspiegels mit einem entsprechend höheren Knochenturnover (Fröhlke 2009). Die Ratte gilt als einziges von der FDA (Food and Drug Administration) anerkanntes „small animal model“; nach Ovarektomie ist sie darüber hinaus das am häufigsten verwendete Osteoporose-Tiermodell. Man kann davon ausgehen, dass innerhalb von 3 Monaten nach durchgeführter Ovarektomie über 50\% der Knochenmasse im Bereich der Tibiametaphyse verloren gehen, also ein mit der postmenopausalen Osteoporose vergleichbarer Zustand entsteht (Seidlová-Wuttke et al. 2003, Wronski et al. 1985). Wir haben bei unseren Untersuchungen auf das „Mature Rat Model“ zurückgegriffen. Dabei sind die Tiere drei Monate alt und damit geschlechtsreif. Eine zu diesem Zeitpunkt durchgeführte Ovarektomie vermeidet, entgegen dem Gebrauch zwölf Monate alter Tiere (Aged Rat Model), die Gefahr einer altersbedingt den Versuchsablauf störenden Verschlechterung der Knochensubstanz (Birner 1995). Frakturen heilen bei älteren Ratten deutlich verlangsamt, bedingt am ehesten durch eine geringere Anzahl an osteogenen Zellen im Periost (O`Driscoll et al. 2001) und im Knochenmark (D`Ippolito et al. 1999), als auch durch Defizite im Bereich der für die Knochenheilung besonders wichtigen Gefäßneubildung (Rivard et al. 1999).

Bisherige Experimentalstudien zur Knochenheilung im Rahmen der Osteoporose wurden in der Regel an der Diaphyse von Femur und Tibia durchgeführt (Cao et al. 2002, Bolander et al. 1992, Schmidmaier et al. 2001). Dementsprechende Studien im Bereich der Metaphyse waren bisher eher die Ausnahme und betrafen spezielle Fragestellungen (Aspenberg et al. 2008, Morgan et al. 2008, Tsiridis et al. 2007). Unser Entschluss, die metaphysäre Tibia zu nutzen entsprach der Erkenntnis, dass bei der humanen Osteoporose überwiegend der metaphysärspongiöse Knochen betroffen ist und somit ein besserer Bezug zur Klinik hergestellt werden kann (Thompson et al. 1995, Claes et al. 2009, Wronski et al. 1985). Dieses geht auch konform mit der Erfahrung, dass sich eine tierexperimentell erzeugte Osteoporose vorwiegend im Bereich der Metaphyse manifestiert. Ein weiteres Argument, die Metaphyse bei den Untersuchungen vorzuziehen, sahen wir auch in der Tatsache einer unterschiedlichen Knochenheilung am kortikalen und spongiösen Knochen: heilt ersterer überwiegend mittels periostalem Kallus, spielt bei letzterem eher die endostale Knochenheilung die entscheidende Rolle (Stürmer et al. 2008 a). Die an der Metaphyse erschwerte Stabilisierung des osteotomierten Knochens erwies sich dabei nicht als methodischer Nachteil. 
Die von uns auf diesem Wege ermittelten und oben dargestellten Ergebnisse sollen im Folgenden auf ihre Relevanz hin überprüft werden.

\subsection{Knochenheilung unter Östrogensubstitution}

Eine reduzierte Östrogenkonzentration kann sowohl den schnellen postmenopausalen Knochenverlust (Typ-I-Osteoporose) als auch den langsameren altersbezogenen Knochenverlust (Typ-II-Osteoporose) induzieren (Riggs et al.1998). Es zeigte sich, dass der physiologische Knochenumbau in Zyklen stattfindet, der durch das Zusammenspiel von Osteoblasten und Osteoklasten gesteuert wird. Östrogen wirkt modulierend auf den Knochenumbau ein, verlängert den jeweiligen Umbauzyklus und schützt in diesem Sinne vor Knochensubstanzverlust (Manolagas et al. 2002). Diese Senkung der Zyklusraten resultiert aus einer gleichzeitigen Suppression der Osteoblasten- und Osteoklastengenese (Syed und Khosla 2005).

Zhou et al. fanden 2001 heraus, dass Östrogengaben bei ovarektomierten Ratten nicht nur vor Knochenverlust schützen, sondern auch zu einer gesteigerten Knochenbildung führen. Bei Frauen konnte als Ergebnis einer Langzeittherapie festgestellt werden, dass die Substitution von Östrogenen sowohl den Knochenabbau als auch die Frakturinzidenz auf das Niveau der Prämenopause senkt (Delmas et al. 1997).

Unsere Studie hatte das Ziel, den medikamentösen Einfluss der Frakturheilung am metaphysären osteoporotischen Knochen in der Frühphase $\mathrm{zu}$ analysieren. Da die Knochenheilung angesichts der von uns gewählten experimentellen Bedingungen unter Kallusbildung abläuft, ergaben die biomechanischen sowie die mikroradiographischen Untersuchungen jeweils direkte Hinweise auf Qualität und Quantität des bis dahin neugebildeten Knochens.

Bei der mechanischen Untersuchung zeigte sich, dass sowohl die Elastizität, als auch die Biegefestigkeit des Kallus gegenüber den Vergleichswerten signifikant erhöht waren. Östrogen verbessert demnach nachweisbar die biomechanischen Eigenschaften des Kallusgewebes. Der positive Effekt der Östrogengabe wird auch im Vergleich zur hormondefizitären Gruppe bestätigt. In Bezug auf die Streckgrenze zeigen sich sogar erhöhte Stabilitätswerte als ein Zeichen dafür, dass das neugebildete Knochengewebe unter Östrogeneinwirkung innerhalb von 5 Wochen optimale Stabilität gegenüber Störkräften gewährleisten konnte.

Die Tatsache, dass Östrogen in der Lage ist, die Widerstandfähigkeit des Kallus nach Fraktur zu erhöhen, konnte auch in einer anderen Studie gezeigt werden (Kolios et al. 2009 b). 
Die insoweit eindeutigen Vorteile der Östrogengabe wurden durch die quantitative Untersuchung des osteotomienahen Kallusgewebes mittels Mikroradiographie bestätigt. Dabei lagen die positiven Effekte eindeutig mehr in der Zunahme der Dichte des Gewebes als in der Dicke. Das bedeutet, dass Östrogen innerhalb der ersten Wochen der Knochenheilung durch Mineralisation des neugebildeten Gewebes die Knochenstabilität steigert und nicht durch rein appositionelles Wachstum. Dabei lagen die Kallusdichtewerte an allen drei untersuchten Stellen (ventral periostal, dorsal periostal, endostal) sogar über denen der Vergleichsgruppe (INT).

Am Trabekelsystem wurden nicht nur Dichte und Dicke gemessen, sondern auch die Zahl der Kreuzungen, da die Verstrebung erhebliche Relevanz für die Stabilität des metaphysären Knochens besitzt. Die Messungen zeigten, dass hier ein besonders starker, negativer Einfluss der Osteoporose festzustellen war (Trabekeldichte: OVX: 1,01\%, INT: 9,13\%); die Ovarektomie führte hier zu einer extremen Verringerung der Knochensubstanz - und zwar sowohl in Bezug auf Dichte, als auf Dicke und Zahl der Kreuzungspunkte. Es bestand hier demnach ein eindrucksvoller Bezug zur klinischen Erfahrung, dass Osteoporosefrakturen in besonderer Weise den metaphysären Knochen betreffen und damit auch unsere Methodik, die metaphysäre Lokalisation zu untersuchen bestätigte. Die positive Wirkung des Östrogens zeigte sich auch hier: die Werte der Gruppe lagen immer um ein mehrfaches höher gegenüber denen der Vergleichsgruppen (Trabekeldichte: 22,86\%). Damit kann gezeigt werden, dass die biomechanisch durchgeführten Messungen mit der mikroradiographisch ermittelten Werten wie Dichte, Dicke und Zahl der Kreuzungspunkte am Trabekelsystem eng korrelieren.

Anhand der Kallusformation dorsal, ventral und endostal ließ sich ebenfalls ein positiver Effekt unter Östrogengabe nachweisen. Verglichen mit den Vergleichsgruppen ergaben sich auch hier die höchsten Werte. Insgesamt zeigte sich ein mit der Kontrollgruppe (INT) vergleichbarer physiologischer Heilungsverlauf besonders dadurch, dass die Fraktur frühzeitig durch endostalen Kallus stabilisiert wurde, wie es für Frakturheilung der gesunden metaphysären Knochen typisch ist (Stürmer et al. 2008 a).

Östrogen führt also eine Optimierung der Stabilität des Gesamtsystems über eine Verbesserung der Knochendichte am Kallusgewebe herbei, ebenso wie über eine Verdichtung der Trabekelstrukturen.

Die lokalen Effekte, sowohl in Bezug auf die Ausbildung einer Osteoporose nach Ovarektomie, als auch in Bezug auf deren Beeinflussbarkeit durch den Knochenaufbau fördernde Präparate, waren an der Kortikalis besonders gering. Gegenüber dem Trabekelsystem und auch dem neugebildeten Kallus ist die Kortikalis erheblich weniger 
durchblutet, sodass reaktive Vorgänge nur mit Verzögerung ablaufen können. Dieses ist an den Ergebnissen auch deutlich abzulesen: in Bezug auf Dichte und auch Dicke der Kortikalis sind die Werte in allen vier Gruppen ohne relevante Unterschiede; damit ist nach unseren Ergebnissen in Bezug auf die Heilung diaphysärer Osteoporosefrakturen durch Östrogengabe kein positiver Einfluss zu erwarten. Diese Ergebnisse unterstreichen bereits bestehende Studien zu der Darstellung, dass Osteoporose keinen Einfluss nimmt auf den metaphysären kortikalen Knochen (Kolios et al. 2009 b, Stürmer et al. 2008 a).

\subsection{Knochenheilung unter Alendronat}

Bisphosphonate sind für ihren positiven Effekt auf den Knochenmineralsalzgehalt bekannt; sie sollen $\mathrm{zu}$ einer therapiebedingten Steigerung der Knochenmasse führen und das Frakturrisiko mindern (Black et al. 1996, Black et al. 2006). Neubildung und Lebensdauer der Osteoklasten werden vermindert, wodurch nicht nur eine Optimierung der Knochendichte sondern auch eine Verbesserung der Mikro- und Makrostruktur des Knochens resultieren soll; weiterhin wird eine Verstärkung der Knochenoberfläche durch Bindung der Bisphosphonate an körpereigene Mineralsalze erreicht (Riggs und Parfitt 2005, Roschger et al. 2001). Ihr klinischer Einsatz ist heute Standard, wobei insbesondere die Nebenwirkungsrate Fragen offen lässt.

Alendronatgaben verbessern nach unseren Biegeversuchen im Vergleich mit der unbehandelten Osteoporosegruppe tatsächlich das systemische Stabilitätsverhalten gegenüber den angewandten Störkräften, gemessen wiederum an Steigung und Streckgrenze. Diese beiden Parameter ergaben, ebenso wie nach Estradiolgaben, auch hier untereinander vergleichbare Ergebnisse, womit die biomechanisch-methodische Aussagekraft unserer Untersuchungen weiter untermauert werden konnte. Mit 25.28N gegenüber 21.04N in Bezug auf die Streckgrenze bzw. 72.07N/mm gegenüber 41.28N/mm in Bezug auf die Steigung hatte der Stabilitätsgewinn jedoch nicht das erwartete Ausmaß. Der im Rahmen unserer Versuchszeit neugebildete Knochen erfüllt damit nicht in ausreichendem Maße das erwünschte Stabilitätsziel. Eine Therapie mit Alendronat kann aus dieser Sicht demnach nur empfohlen werden, wenn aus klinischer Gesamtschau heraus keine medikamentöse Alternative verfügbar ist. Eine deutlich höhere Effizienz ergab sich nach Estradiolgaben, sodass aus rein biomechanischer Sicht die Aussage getroffen werden kann, dass Estradiolgaben zur Stabilisierung des osteoporotischen Knochens im Rahmen der Frakturheilung die höhere Effizienz zukommt. 
Betrachtet man die mikroradiographischen Untersuchungen, so ließ sich der Trend einer nur begrenzten Effektivität der Alendronatgabe auch hier in nahezu allen morphologisch untersuchten Arealen nachweisen. In Bezug auf die Kallusdichte, ein wesentlicher Parameter für den erreichten Mineralisationsgrad des neu gebildeten Gewebes, ergaben sich an den drei Untersuchungsorten (ventral-periostal, dorsal-periostal und endostal) gegenüber der Estradiolgruppe deutlich schlechtere Werte, wobei endostal sogar der Wert der unbehandelten Osteoporosegruppe unterschritten wurde. Auf die Dicke des Kallusgewebes hatte das Alendronat, ebenso allerdings wie Estradiol, keinen Einfluss. Auffallend war allerdings, dass die Alendronatwerte dorsal sogar noch unter denen der unbehandelten Osteoporosegruppe lagen. Erklärbar wird der mangelnde Medikamenteneinfluss wenn man berücksichtigt, dass in unseren Versuchen osteoporosebedingt in Bezug auf die Kallusdicke kaum Defizite auftraten. Messtechnische Differenzen zwischen den Gruppen von unter 1mm konnten dabei nicht als aussagekräftig bezeichnet werden. Damit liegt eine Schwachstelle der metaphysären Osteoporose ganz allgemein offenbar darin, dass der nach Frakturen zunächst ausreichend gebildete Kallus nicht adäquat ausreift.

Die duch antiresorptive Eigenschaften zu erwartende und in Vergleichsuntersuchungen auch gefundene Tendenz zur Bildung ausgedehnter Kallusformationen unter Alendronatgabe konnte von uns nicht bestätigt werden, wobei die Ursache in einer bei diesen Untersuchungen teilweise deutlich längeren Überwachungszeit liegen könnte ebenso wie an einem von unserer Untersuchung differenten, meist diaphysären Knochenareal (Cao et al. 2002, Cao et al. 2007, Manabe et al. 2009). Gerade metaphysär mit seiner im wesentlichen nach intraossär ausgerichteten Knochenheilung ist Alendronat innerhalb der ersten fünf Wochen wirkungsarm, da die rechtzeitige und ausreichende Verkalkung des neu gebildeten Geflechtknochengewebes ausbleibt, der Kallus bleibt unreif. Bestätigt wird dieses durch Untersuchungen mittels Sequenzmarkierung welche eindeutig zeigen konnten, dass prinzipiell nach Alendronatgabe gerade in der Frühphase der Knochenheilung endostales Knochengewebe angelegt wird, die biologischen Voraussetzungen also durchaus gegeben sind (Kolios et al. 2009 a). Dieser frühe Geflechtknochen ist aber zum Erreichen der erwünschten und notwendigen Festigkeit auf ein kontinuierliches Remodelling angewiesen, wobei der letztlich tragfähige lamelläre Knochen im Wesentlichen durch sukzessive gesteigerte Mineralisation entsteht. Wird ein solches Remodelling z.B. durch Alendronat verhindert oder verzögert, entsteht mechanisch unzulänglicher Geflechtknochen (Cao et al. 2002, Cao et al. 2007). Man muss bezweifeln, ob der dem Alendronat neben der Hemmung der Osteoklastentätigkeit zugeordnete Effekt einer knöchernen Verstärkung über Bindung an 
lokale Mineralsalze wirklich in erwünschtem Maße besteht, zumindest in dieser Frühphase der Knochenheilung. Wäre es so, müsste man es anhand der mikroradiographischen Technik anhand einer gesteigerten Knochendichte nachweisen können. Eine ähnlich verringerte Mineralisationsrate, verbunden mit einer ebenso verringerten Mineralisationsoberfläche am Knochen wurde im Vergleich zu Kontrollgruppen auch am Affen bereits gefunden und auf eine durch Alendronat zu stark verminderte Osteoklastenabbautätigkeit zurückgeführt, also ein Defizit auf zellulärer Ebene (Manabe et al. 2009). Dadurch bedingte Änderungen in der Mineralsalzverteilung am Knochen und Verzögerung der Kollagenreifung werden als Ursache der knöchernen Stabilität ebenfalls diskutiert (Boskey et al. 2008).

Die oben angegebenen Estradiolvergleichswerte zeigen demgegenüber, dass nach Gabe dieses Medikamentes die beiden für die Frakturheilung wesentlichen Faktoren „Gewebsneubildung" und „Mineralisation" bereits in der Frühphase der Knochenheilung in höherem Maße zusammenfallen und so das Stabilitätsergebnis entscheidend verbessern.

Der bereits oben beschriebene und in Bezug auf die Estradioltherapie kommentierte Zustand des nach Ovarektomie veränderten Trabekelsystems mit seiner extremen intraossären Knochenstrukturausdünnung konnte durch Alendronat ebenfalls nicht relevant beeinflusst werden. Die Differenzen zu dem hier besonders effizienten Estradiol waren außerordentlich groß und zwar in allen untersuchten Belangen. Dichte und Dicke der abgebildeten Trabekelstrukturen, sowie insbesondere auch die Zahl der stabilisierenden Kreuzungen blieben auch nach Alendronatgaben sehr niedrig; ein allenfalls gering positiver Einfluss war in Bezug auf die Knotenzahl festzustellen. Die untersuchten Präparate wiesen durch die experimentell herbeigeführte Osteoporose die insgesamt auffallendsten Negativresultate auf; es wurde die Bedeutung des intraossär- trabekulären Systems als Risikofaktor im Rahmen einer metaphysären Osteoporose besonders deutlich und damit auch die Notwendigkeit, gerade hier besonders effektive Verbesserungsmöglichkeiten therapeutischer Art zu erhalten. Noch mehr als durch die Untersuchungen am Kallus zeigen damit die Ergebnisse am Trabekelwerk, dass Alendronat zur Behandlung einer metaphysären Osteoporose bzw. zur Optimierung der Bruchheilung im Rahmen einer solchen Erkrankung nicht geeignet ist. Der mikroradiographisch gefundene Effekt in Bezug auf eine Verbesserung von Trabekeldichte und - dicke sowie auf die Dichte der Kreuzungspunkte ist so gering, dass man in der Praxis keinen vernünftigen Therapieeffekt erwarten kann.

Entgegengesetzt zu den osteoporosebedingten Veränderungen an der diaphysären Kortikalis waren solche im Bereich der Metaphyse nach unseren Untersuchungen völlig bedeutungslos. Die Osteoporose erbrachte an der Kortikalis keinerlei Defizite, sodass medikamentös auch 
kein Effekt auf die gemessene kortikale Dicke und Dichte erwartet werden konnte. Dieses steht in Übereinstimmung zu anderen experimentellen Untersuchungen, bei denen ebenfalls im Rahmen der Osteoporose keine wesentlich negative Beeinflussung der metaphysären Kortikalis zu sehen war (Stürmer et a. 2008 a, Stürmer at al. 2008 b, Kolios et al. 2009 b). Eine gerade publizierte Untersuchung mittels XCT an der distalen menschlichen Radiusmetaphyse ergibt demgegenüber erstmals einen Hinweis auf die Bedeutung auch des metaphysär-kortikalen Knochenverlustes, unter Umständen bedingt aber durch methodische Unterschiede: das neuartige, hochauflösende CT mag ebenso eine Rolle gespielt haben wie die Tatsache, dass die Untersuchungen im Verlauf der chronischen humanen Erkrankung und nicht innerhalb von wenigen Wochen nach einer experimentell gesetzten Fraktur bei einer Ratte erhoben wurden (Zebaze et al. 2010). Dieser methodischen Defizite waren sich die Autoren bei Erstellung des Studiendesigns bewusst, war es doch das umgrenzte Ziel dieser Arbeit, den medikamentösen Einfluss klinisch relevanter Medikamente im Kurzzeitvergleich zum gesunden und osteoporotischen Knochen der Ratte zu analysieren. Immerhin wird man insoweit die Entwicklung im Auge behalten müssen.

\subsection{Klinische Relevanz der Ergebnisse}

Trotz des in unserer Studie eindrucksvoll dargestellten positiven Effektes der Östrogene auf die Heilung des osteoporotischen Knochens, muss jedoch die Übertragbarkeit der Ergebnisse auf den klinischen Bereich mit anderen Erkenntnissen und Studien diskutiert werden.

Die primär-präventive Wirkung der Hormonersatztherapie (HRT) bei Osteoporose konnte in zahlreichen klinischen Studien belegt werden. So wurden unter Einsatz von HRT sowohl eine Zunahme der Knochendichte wie auch eine reduzierte Frakturinzidenzrate um 30 bis 40\% nachgewiesen. Eine signifikante Frakturreduktion bei Osteoporose nach ebenfalls prophylaktischer Östrogengabe beschrieben bereits Popp und Lippuner 2005.

Die klinischen Richtlinien in Bezug auf die präventive Östrogentherapie der postmenopausalen Osteoporose haben sich in den letzten Jahrzehnten ständig gewandelt. Gestützt auf klinische und tierexperimentelle Studien bestand zunächst eine hohe Akzeptanz der HRT. Neue Aspekte eröffneten sich jedoch nach Vorliegen der „One - Million - Women Studie" 2003 sowie der „WHI-Studie“ 2002 (Beral 2003). So zeigte sich nach der prophylaktischen Gabe von Östrogenen ein gehäuftes Auftreten von Brustkrebs, Thrombosen sowie von Herzinfarkt und Schlaganfällen. Die lokalen Einflüsse auf den Knochen traten gegenüber den festzustellenden Nebenwirkungen nahezu vollständig in den Hintergrund, mit der Folge einer wesentlichen Einschränkung der Indikation. Erst allmählich wich die 
anfängliche Skepsis gegenüber der Östrogentherapie nach Veröffentlichung der neuesten Studienergebnisse einer differenzierteren Betrachtungsweise mit dem Ziel, durch Modifikation von Dauer und Höhe der Östrogengabe die Nebenwirkungsrate zu reduzieren (Tarakida et al. 2007). Laut der Arzneimittelkommission der deutschen Ärzteschaft gilt die Verwendung von Hormonpräparaten bei der Behandlung von Osteoporose zwar als Ausnahmefall, doch hinsichtlich der oben diskutierten Untersuchungen und einer RisikoNutzen-Abwägung, sind Östrogene zum richtigen Zeitpunkt und in einer entsprechend niedrigen Dosierung über einen kurzen Zeitraum eingesetzt auch weiterhin klinisch verwendbar (Fröhlke 2009). Dieses Vorgehen scheint im Hinblick auf unsere eigenen Ergebnisse durchaus angemessen und würde einen medikamentösen Einsatz unter Nutzung der lokalen Vorteile zulassen. Da es sich um eine Kurzzeituntersuchung handelt, bestätigen die Ergebnisse, dass die kurzfristige Gabe von Östrogen gleichermaßen die Prävention und Therapie der osteoporotischen Fraktur begünstigt.

Ordnet man z.B. die WHI - Studie in diese Überlegungen ein, so stellt man zunächst fest, dass diese aufgelegt wurde, um Nebenwirkungen einer Östrogentherapie auf das Herz Kreislaufsystem zu evaluieren. Das durchschnittliche Behandlungsalter der Patientinnen war mit einem Durchschnitt von 10 Jahren nach der Menopause relativ hoch, die Östrogenmedikation war, gemessen an Dauer (7,4 Jahre) und Dosierung $(0,625 \mathrm{mg} / \mathrm{Tag})$ ebenfalls hoch. Zudem wurden hysterektomierte Frauen aus der Studie ausgeschlossen, während ein Gestagenschutz zur Uteruskarzinomprophylaxe verabreicht wurde. Wir finden also ein diskussionsbedürftiges Studiendesign, welches auch zu ablehnenden Äusserungen geführt hat (Klaiber et al. 2005).

In Bezug auf die hormonmangelbedingte Osteoporose mit ihren Folgeproblemen hat sich heute der von einer Vielzahl internationaler Richtlinien gestützte Konsens ergeben, von einer durch die beiden großen klinischen Studien induzierten rigorosen Ablehnung abzugehen und eine kurzfristige und niedrig dosierte Östrogenprophylaxe im Sinne einer Nutzen-RisikoAbwägung bei hohem Frakturrisiko und fehlender medikamentöser Alternative zu empfehlen. In der Literatur existieren unterschiedliche Angaben dazu, ob eine frühzeitig nach der Menopause durchgeführte kurzfristige Prophylaxe auch nach Absetzen derselben auf Dauer ihren Effekt nicht verlieren wird. Während Bagger einen Langzeiteffekt sieht, wird ein solcher von Heiss und Yates abgelehnt (Bagger et al. 2004). Weitere Untersuchungen dazu sind offenbar notwendig, um das klinische Vorgehen abzusichern. Der Wert der Östrogenmedikation dürfte aber dementsprechend zunächst wohl eher in der Frühzeittherapie nach eingetretener Fraktur liegen, als in der generellen Prophylaxe. 
In Bezug auf den klinischen Einsatz von Alendronat kann nach unseren Untersuchungen keine Empfehlung abgegeben werden. Die positiven Effekte am Knochen sind gering und denen durch Östrogengabe deutlich unterlegen, sodass eine Indikation im Rahmen einer Prophylaxe und Therapie der osteoporosebedingten Fraktur unserer Meinung nach nicht gegeben ist. Der Einsatz muss dementsprechend auf spezielle Indikationen begrenzt werden, entsprechende negative Begleiterscheinungen der Medikation müssen beachtet werden. Diese Erkenntnis steht im Gegensatz zu anderen Studien. So wird Alendronat weiterhin als ein Mittel der ersten Wahl angesehen, unter anderem zur Reduktion von vertebralen und Hüftfrakturen. Hierbei zeigte sich eine Verringerung von bis zu 50\% (Cranney et al. 2002 a, Cranney et al. 2002 b). Die Dosis wurde auf eine höhere Dosis einmal pro Woche statt einer täglichen Gabe verändert und ein deutlicher Rückgang der Nebenwirkungen, wie z.B. ösophagealer Reflux, erzielt (Hoc 2004). Die Unterschiede in den Ergebnissen zwischen unserer Arbeit und anderen Studien, wie beispielsweise der FIT-Studie („Fracture Intervention Trial“"), lassen sich mit der Dauer der Untersuchung erklären, so wurde für die FIT-Studie beispielweise ein Zeitraum von 8 Jahren in Anspruch genommen (Marcus et al 2002). Mc Clung publizierte ergänzend eine 6-Jahresstudie in der er zeigen konnte, dass postmenopausale Frauen im Vergleich $\mathrm{zu}$ einer Placebogruppe deutlich weniger Knochensubstanzverlust erlitten (Mc Clung et al. 2004). Ein Vergleich mit einer Östrogensubstitution bewies in einer Vorstudie bessere Ergebnisse nach HRT (Ravn et al. 1999).

Abschließend sind demnach beide Medikamente nur unter strenger Nutzen-Risiko-Abwägung einsetzbar, wobei wir nach unseren Ergebnissen einen eindeutigen Vorteil auf Seiten des Östrogens sehen.

\subsection{Bezug der Untersuchungen zur Zahnmedizin}

Ziel dieser Arbeit war es, mit Hilfe des gewählten experimentellen Ansatzes die pathophysiologischen Abläufe im Rahmen der Frakturheilung bei hormondefizitärer Osteoporose unter dem medikamentösen Einfluss von Östrogen und Alendronat weiter klären $\mathrm{zu}$ helfen und so unter Nutzung der gefundenen Ergebnisse den aktuellen therapeutischen Ansatz im Bereich der Osteoporosetherapie zu bestätigen bzw. zu präzisieren. Abschließend gilt es festzustellen, ob auch für den zahnmedizinischen Bereich relevante Rückschlüsse möglich sind.

Prinzipiell müsste das „Osteoporoseproblem" auch für die Zahnmedizin erhebliche Bedeutung haben; Frakturen dieses Bereiches sind zwar selten, aber die Funktionalität der Zähne hängt 
doch in besonderem Maße von einem soliden Kieferknochenangebot ab. Es stellt sich also die Frage, ob die Osteoporose auch am Kieferknochen negative Folgen hat und weiterhin, ob die hier allgemein geltenden Therapiekonzepte das Gebiet der Zahnmedizin berühren.

Wenn auch die hormondefizitäre Osteoporose im zahnmedizinischen Alltag zunächst keine wesentliche Rolle zu spielen scheint, hat doch eine englisch-amerikanische Arbeitsgruppe am Rattenmodell eindeutig herausarbeiten können, dass Östrogenmangel am Kieferknochen (hier Unterkiefer) zur Verminderung der Knochensubstanz führt (Yang et al. 2004). Nicht beantwortet wird dabei die Frage, ob der knochenstrukturell sehr unterschiedliche Oberkiefer ebenfalls betroffen ist. Auch Tanaka und White haben solche Ergebnisse an der Ratte und am Patienten beschrieben (Tanaka et al. 2003, White und Rudolph 1999). Demgegenüber werden solche negativen Einflüsse von anderen Autoren nicht gesehen und somit die Entstehung einer Östrogenmangelbedingten Minderung der Knochensubstanz am Kiefer abgelehnt (Hara et al. 2001, Jiang et al. 2003). Diese unterschiedliche Untersuchungslage erhielt dadurch eine für die Klinik unter Umständen interessante Wende, dass es Mitarbeitern einer Arbeitsgruppe (Yang et al. 2004) gelang, einen klinischen Osteoporosetest für den Kiefer zu entwickeln und so den Übergang vom Tierexperiment zur Klinik herzustellen (Devlin et al. 2007, Horner et al. 2007). Mit diesem „Osteodent-Projekt" wurde an 660 älteren weiblichen Patienten eine Korrelation zwischen einer geminderten Kieferknochendichte, gemessen an Panoramaschichtaufnahmen, und Referenztests an Wirbelsäule und Hüfte hergestellt. Ausgeprägte Erosionen sollen vor allem bei postmenopausalen Frauen ein Zeichen für niedrige Knochenmineraldichte im Rahmen einer Osteoporose sein (Götz 2010). Wenn auch damit noch kein endgültig klinisch gesichertes Diagnostikum geschaffen werden konnte, liegt jedoch nahe, dass am Kieferknochen bei Vorliegen einer Östrogenmangelosteoporose ähnliche strukturell-pathologische Abläufe vorliegen, wie am übrigen Skelett.

Diskutiert wird aus klinischer Sicht auf dem Boden dieser Überlegungen noch am ehesten, ob ein Zusammenhang zwischen Osteoporose und Parodontitiden besteht. Ähnlichkeiten in Bezug auf Pathogenese und Risikofaktoren lassen die Frage aufkommen, ob ein Teil des parodontalen Knochenabbaus auch durch systemischen Abbau bei Osteoporose bedingt sein könnte oder ob eine Osteoporose die Aktivierung entzündlicher Vorgänge am Zahnhalteapparat begünstigt (Gomes-Filho et al. 2007, Lerner 2006). Mehrere in den letzten Jahren erstellte Studien wollen eine Assoziation von Osteopenie bzw. Osteoporose mit dem Auftreten von Parodontitiden und dadurch bedingtem Zahn- und Knochenverlust bei postmenopausalen Frauen festgestellt haben; andere Studien haben eine solchen Zusammenhang nicht bestätigen können (Dervis 2005, Geurs 2007). Auch eine Korrelation 
zwischen Knochenmineralsalzdichte am Unterarm und parodontalem Attachmentverlust wurde gefunden (Brennan et al. 2007). Nach Gomes - Filho et al. spielt die Osteoporose keine Rolle in Bezug auf die Ätiologie der Parodontose, kann aber negative Auswirkungen auf bereits bestehende Veränderungen haben. Nach den „Leitlinien des Berufsverbandes der Fachzahnärzte und Spezialisten für Parodontologie (DGP) zur Betreuung parodontal erkrankter Patienten wird eine Osteoporose als Risikofaktor eingestuft; therapeutische Konsequenzen in Bezug auf eine medikamentöse Bekämpfung der Grunderkrankung werden allerdings bisher nicht gefordert. Zusammenfassend kann man angesichts der klinischen Bedeutung sowohl der Osteoporose als auch der Parodontose und der doch noch relativ unsicheren Datenlage nur weiteren klärenden Studien mit Interesse entgegensehen. Gefordert ist damit eine engere fachliche Verbindung zwischen Allgemein - und Zahnmedizin.

Gruber, als Zahnmediziner, hat sich einer solchen Verknüpfung zahn- und allgemeinmedizinischer Gesichtspunkte gewidmet (Gruber 2006). Ausgehend von den pathophysiologischen Grundlagen der Osteoporose ging er besonders auf Probleme der Implantologie ein, speziell solche der Implantatverankerung, und stellte die Bedeutung des Implantatlagerrisikos bei strukturellen Defiziten auf dem Boden einer Osteoporose heraus. Somit wurde auf die Möglichkeit des Entstehens von knöchernen Substanzdefekten auch durch Allgemeinerkrankungen hingewiesen, welche ansonsten eher mit einer Involution bei Zahnverlust verbunden sind. Bei Gefahr des Unterschreitens von Mindestabständen zu den umgebenden Gewebsstrukturen (am Oberkiefer zur Kieferhöhle, am Unterkiefer zu den Nn. alveolaris inferior und mentalis) ergibt sich die Notwendigkeit häufig aufwändiger Knochenaufbaumaßnahmen, ebenso wie auch im Rahmen der Prothetik Konstruktion und Zahnaufstellung erschwert werden.

Es ist wohl eindeutig, dass heute im Bereich der Zahnmedizin der endogene Mangel an gebrauchsfähiger Knochenstruktur im Wesentlichen mit dem Arbeitsfeld der Implantologie verbunden ist und damit angesichts der rasch steigenden Fallzahlen immer mehr an Bedeutung gewinnt. Operative Techniken zur Implantatlagerverdichtung sind klinische Routine geworden und experimentell abgesichert, unabhängig von der Genese der Rarefizierung (Boyne und James 1980). Damit wäre prinzipiell auch die argumentative Grundlage geschaffen, zur Verdichtung des Knochenlagers normaler und künstlicher Zähne auch diejenigen medikamentösen Schritte einzuleiten, welche bei der Osteoporose nach derzeitigem Konsens erfolgreich sind. Jede Kräftigung des Lagerknochens, ob medikamentös oder operativ herbeigeführt, muss erwünscht sein, ob zur Frakturprävention oder Zahnknochenlageroptimierung angewandt. 
Überprüft man allerdings die in Bezug auf den medikamentös unterstützten Knochenaufbau existenten klinischen Erfahrungen aus Sicht der Zahnmedizin so stößt man sofort auf Probleme, welche sich im Wesentlichen auf den Einsatz von Bisphosphonaten beziehen. Nach deren Einsatz im Rahmen der Osteoporose- und auch Tumortherapie ist reproduzierbar ein spezifisch kieferchirurgisches Problem aufgetreten, welches Medikamente dieser Substanzgruppe in die Diskussion gebracht hat. Alendronat, als wesentlicher Vertreter der Bisphosphonate, ist nach gängiger Erfahrung in der Lage die Knochendichte zu verbessern; offenbar wirkt es, ebenso wie Östrogen, auch am Alveolarknochen einem Substanzverlust entgegen (El-Shinnawi und El-Tantawy 2003). Der nach langfristiger Behandlung resultierende Zuwachs der Knochenhartsubstanz bedeutet allerdings gleichzeitig weniger Raum für Gefäße und damit prinzipiell weniger Möglichkeiten für die davon abhängigen Zellen (z.B. auch der Immunabwehr), Wirksamkeit zu entfalten. Darüber hinaus wird auch der Abstand der in den Knochen eingemauerten Osteozyten von den ernährenden Gefäßen vergrößert, wodurch die Vitalität der Knochenhartsubstanz gefährdet wird. Dementsprechend besteht in bestimmten Bereichen des Skeletts bei hochdosierter Therapie mit Bisphosphonaten das Risiko der Fragilität des Knochens und darüber hinaus auch der lokalen Nekrose durch Reduktion der Osteozytenzahl.

Kommt es in gefährdeten Bereichen zur Keimbesiedlung, ist die ungenügend vitalisierte Hartsubstanz einer solchen schutzlos ausgeliefert. Es resultiert das Bild der infizierten Kieferknochennekrose, sobald Keime im Rahmen einer Parodontose oder aber nach operativen Eingriffen an die Knochenoberfläche gelangen. Genau diese negativen Erfahrungen sind in reproduzierbarer Zahl am Kieferknochen gemacht worden (Felsenberg et al. 2006). Diese gelten im Wesentlichen für die im Rahmen der Tumortherapie eingesetzten sehr hohen Dosen. Eine Osteonekroseprävalenz bei oraler Einnahme von Alendronat in Höhe von $0,001 \%$ und $0,07 \%$ wird angegeben und dementsprechend eine engmaschige zahnärztliche Überwachung empfohlen (Kunchur und Gross 2008, Schindler und Kirch 2008). Zusätzliche Risikofaktoren sind bekannt, so zum Beispiel durch eine gleichzeitig erforderliche Strahlentherapie. Professionell überwachte Maßnahmen der Parodontoseprophylaxe sind zu beachten, wobei mehr auf den Parodontalzustand zu achten ist, als auf die kariöse Progredienz (Grötz 2003). Frühsymptome drohender Osteonekrosen sind neben intraoralen Fistelbildungen auch Gefühlsstörungen im Bereich des N. alveolaris inferior. Differentialdiagnostisch sind metastatische Infiltrationen des Kieferknochens auszuschließen (Otto S et al. 2009). Bei anamnestisch oder klinisch bestehendem Verdacht auf das Vorliegen einer bisphosphonatbedingten Knochennekrose sollten Implantate nur 
verwendet werden, wenn keine vernünftige Therapiealternative gegeben ist; auf eine besonders intensive Nachsorge ist zu achten (Strack und Epker 1995).

Aus Sicht der Zahnmedizin scheint es daher angebracht, auf den therapeutischen Einsatz von Bisphosphonaten so weit wie möglich zu verzichten. Eine solche Forderung kann, selbstverständlich unter Beachtung der hier gegebenen methodischen Voraussetzungen, durch die von uns gefundenen Ergebnisse ohne weiteres gestützt werden. Es ergibt sich danach bei Kurzzeitüberwachung der Heilung einer Fraktur, besonders im Vergleich zum Östrogen, für einen derartigen medikamentösen Einsatz klinisch kein Raum. Die scheinbare Diskrepanz zwischen dem von uns festgestellten mangelnden Früheffekt in Bezug auf den Knochenaufbau einerseits und dem Langzeitproblem der überschießenden Hartsubstanzbildung andererseits erklärt sich wohl dadurch, dass eine Osteoklastenhemmung in der Frühphase der Frakturheilung nicht entscheidend förderlich ist, während auf Dauer eine unabhängig von der Frakturheilung ungebremst sich fortsetzende Neubildung von Knochenhartsubstanz dessen Vitalität zunehmend gefährdet. 


\section{Zusammenfassung}

Die Östrogenmangel-bedingte Osteoporose mit ihren Komplikationen stellt nach wie vor nicht nur ein medizinisches, sondern auch ein sozioökonomisches Problem dar. Einerseits ist die Zahl der altersbedingt Betroffenen hoch und wird aus demographischen Gründen weiter ansteigen, andererseits wird die Diagnose angesichts unzureichender Präventivmaßnahmen häufig erst gestellt, wenn es angesichts der geschwächten Mikroarchitektur des Knochens zu Frakturen infolge von Bagatelltraumata gekommen ist. Betroffen sind dann überwiegend metaphysäre Skelettabschnitte; neben der Frakturinzidenz spielt auch die verzögerte Bruchheilung eine nachteilige Rolle.

Die bisher zu Prävention und Therapie in besonderem Maße genutzten medikamentösen Maßnahmen betreffen zwei unterschiedliche Präparategruppen: die Östrogene sowie die Bisphosphonate. Die zweifelsfrei damit erzielten Fortschritte werden allerdings bis heute von lokalen und systemischen Nebenwirkungen überlagert, sodass sowohl in Bezug auf Dosierung als auch Dauer der Medikation noch Fragen offen sind.

Die vorliegende Arbeit beschäftigt sich mit diesem Problem; anhand eines standardisierten Rattenmodells soll die Frage beantwortet werden, ob Östrogen bzw. Alendronat die Knochenheilung der Tibiametaphyse im Rahmen einer ovarektomieinduzierten Östrogenmangelosteoporose in der Frühphase beeinflusst. Das nach Tibiaosteotomie innerhalb der ersten fünf postoperativen Wochen produzierte Kallusgewebe wurde dazu qualitativ und quantitativ mittels Biegeversuch und Mikroradiographie untersucht. Nach Auswertung der Ergebnisse wurde deren Bedeutung für klinische Medizin und Zahnmedizin diskutiert.

Unsere Ergebnisse zeigten gleichermaßen biomechanisch und mikroradiographisch, dass die Östrogentherapie einer solchen mit Alendronat deutlich überlegen ist. Gegenüber einer Vergleichsgruppe ohne medikamentöse Therapie konnten in Bezug auf die Biegefestigkeit und die planimetrisch bestimmte Kallusmenge erhebliche Verbesserungen, bis hin zu sich der Norm annähernden Werten gefunden werden. Dabei wurde die für die metaphysäre Frakturheilung besonders wichtige intraossäre Knochenneubildung besonders positiv beeinflusst. Alendronat zeigte demgegenüber - und zwar durchgängig bei allen Untersuchungen - nur eine geringfügig positive Wirkung.

Für die Klinik ergibt sich aus unseren Untersuchungen - unter Vorbehalt des Rattentiermodells - die Forderung, Östrogen in Prophylaxe und Therapie der Hormonmangelosteoporose grundsätzlich auch weiterhin zu berücksichtigen. Da durch große 
Feldstudien das Risiko von Nebenwirkungen einer Östrogenbehandlung nachgewiesen wurde, muss der Einsatz begrenzt werden; die derzeit gültigen klinischen Richtlinien empfehlen damit auch einen solchen für einen möglichst kurzen, nur die Frühphase betreffenden Zeitraum. Da bei unseren Untersuchungen eine positive Wirkung auf den Knochen in genau diesem Zeitraum festgestellt wurde, besteht von daher eine gute Übereinstimmung. Der klinische Einsatz von Bisphosphonaten kann nach unseren Ergebnissen im Rahmen der Frakturprävention und -therapie nur dann unterstützt werden, wenn therapeutische Alternativen fehlen; eine nur relativ geringe Wirkung am Knochen muss in Kauf genommen werden.

Für die Zahnmedizin spielt die osteoporosebedingte Fraktur zunächst keine Rolle. Fragen der Knochenstruktur erlangen allerdings bei den heutigen Möglichkeiten der Implantologie zunehmende Bedeutung. Östrogen kann somit auch hier für eine Optimierung sorgen. Knochenaufbausubstanzen bedingen allerdings bei längerfristiger Applikation das Risiko einer offenbar den Kieferknochen besonders betreffenden Strukturverdichtung, welche durch Einschränkung der Gefäßversorgung besonders nach Bisphosphonatgaben Kiefernekrosen zur Folge hat. Durch die begleitende Infektionsgefahr wird die Indikation zum Einsatz von Implantaten erheblich reduziert bzw. die Komplikationsrate erhöht. Eine von daher erwünschte Reduktion der Bisphosphonatmedikation kann nach unseren Untersuchungen unterstützt werden, da ihre positive Frühwirkung im Rahmen der Frakturheilung äußerst begrenzt ist. Langzeitbehandlungen führen aber $\mathrm{zu}$ einer unphysiologisch hohen Knochenverdichtung und müssen aus zahnmedizinischer Sicht möglichst vermieden werden. 


\section{Literaturverzeichnis}

Aarden EM (1994): Functions of osteocytes in bones. Cell Biochem 55, 287-299

Allgöwer M (1964): Osteosynthese und primäre Knochenheilung. Langenbecks Arch Chir $\underline{308}$

Aubin JE (2001): Regulation of osteoblast formation and function. Rev Endocr Metab Disord 2, 81-94

Aspenberg P, Wermelin K, Tengwall P, Fahlgren A (2008): Additive effects of PTH and bisphoshonates on the bone healing response to metaphyseal implants in rats. Acta Orthop 79: 111-15

Augat P, Simon U, Liedert A, Claes L (2005): Mechanics and mechano-biology of fracture healing in normal and osteoporotic bone. Osteoporos Int 16: 36-43

\section{Bagger Yu Z, Tanko LB , Alexandersen P, Hansen HB, Møllgaard A, Ravn P, Kanis J,} Christiansen C (2004): Two to three years of hormone replacement treatment in healthy women have long-term preventive effects on bone mass and osteoporotic fractures: the PERF study. Bone 34: 728-735

Barrios C, Brostrom LA, Stark A, Walheim G (1993): Healing complications after internal fixation of trochanteric hip fractures: the prognostic value of osteoporosis. $\mathbf{J}$ Orthop Trauma 7: 438-442

Bartl R Osteoporose: Prävention- Diagnostik- Therapie. Thieme, Stuttgart; New York 2001

Basset CAL (1972): Clinical implications on cell function in bone. Clin Orthop 87, 49

Becker S, Ogon M Ballonkyphoplastie. Springer, Wien 2006

Benninghoff A, Drenckhahn D Anatomie: makroskopische Anatomie, Embryologie und Histologie des Menschen. Band 1, 15. Auflage; Urban \& Schwarzenberg, München 1994 
Beral V, Million Women Study Collaborators (2003): Breast cancer and hormonereplacement therapy in the Million Women Study. Lancet $\underline{362}$, 419-427

Birner H Biochemische Marker des Knochenstoffwechsels bei der Ratte und beim Menschen, Vitamine als Prophylaxe im Osteoporose-Modell Ratte. Vet. Med. Diss., München 1995

Black DM, Cummings SR, Karpf DB, Cauley JA, Thompson DE, Nevitt MC, Bauer DC, Genant HK, Haskell WL, Marcus R et al. (1996): Randomised trial of effect of alendronate on risk of fracture in women with existing vertebral fractures: FractureIntervention Trial Research Group. Lancet 348: 1535-41

\section{Black DM, Schwartz AV, Ensrud KE, Cauley JA, Levis S, Quandt SA, Satterfield}

S, Wallace RB, Bauer DC, Palermo L et al. (2006): Effects of continuing or stopping alendronate after 5 years of treatment: the Fracture Intervention Trial Long-term Extension (FLEX): a randomized trial. JAMA 296: 2927-38

Bolander ME, Sabbagh R, Jeng C (1992): Östrogen treatment during fracture repair strengthens healing callus in an osteoporotic model. Trans Orthop Res Soc 17: 138

Bord S (1996): Production of collagenase by human osteoblasts and osteoclasts in vivo. Bone $\underline{19}, 35-40$

Boskey AL, Spevak L, Weinstein RS (2008): Spectroscopic markers of bone quality in alendronate-treated postmenopausal women. Osteoporos Int. Published online September 04, 2008; PMID: 18769963

Boyne PJ, James RA (1980): Grafting of the maxillary sinus floor with autogenous marrow and bone. J Oral Surg $\underline{38}$, 613-616

Brennan RM, Genco RJ, Hovey KM, Trevisan M, Wactawski-Wende J (2007): Clinical attachment loss, systemic bone density, and subgingival calculus in postmenopausal women. $\mathbf{J}$ Periodontol $\underline{78}, 2104-2111$ 
Brookes M (1960): The vascular reaction of tubular bone to ischaemia in peripheral occlusive vascular disease. J Bone Joint Surg $\underline{423}, 110$

Cao Y, Mori S, Mashiba T, Westmore MS, Ma L, Sato M, Akiyama T, Shi L, Komatsubara S, Miyamoto K, Norimatsu H (2002): Raloxifene, Östrogen and Alendronate affect the processes of fracture repair differently in ovariectomized rats. J Bone Miner Res 17: 2237-46

Cao Y, Mori S, Mashiba T, Kaji Y, Manabe T, Iwata K, Miyamoto K, Komatsubara S, Yamamoto T (2007): 1Alpha,25-dihydroxy-2beta(3hydroxypropoxy)vitamin D3 (ED-71) suppressed callus modelling but did not interfere with fracture healing in rat femora. Bone 40: 132-9

Claes L, Veeser A, Göckelmann M, Simon U, Ignatius A (2009): A novel model to study metaphyseal bone healing under defined biomechanical conditions. Arch Orthop Trauma Surg 129: 923-928

Clark EA, Goodship AE, Lanyon LE (1975): Locomotor bone strain as the stimulus for bone`s mechanical adaptability. J Physiol 245, 57

Cranney A, Tugwell P, Adachi J, Weaver B, Zytaruk N, Papaioannou A, Robinson V (2002 a): Meta-analysis of risedronate for the treatment of postmenopausal women. Endocr $\operatorname{Rev} \underline{23}, 515-23$

Cranney A, Wells G, Willan A, Griffith L, Zytaruk N, Robinson V, Black D (2002 b): Meta-analysis of alendronate for the treatment of postmenopausal women. Endocr Rev $\underline{23}$, 508-16

Curtis R, Goldhahn J, Schwyn R, Regazzoni P, Suhm N (2005): Fixation principles in metaphyseal bone-a patent based review. Osteoporos Int.16, 54-64

DAGO (Deutsche Arbeitsgemeinschaft Osteoporose) Osteoporose Leitlinien- Die Empfehlung der Deutschen Arbeitsgemeinschaft Osteoporose. Kilian, Marburg 1996 
Debrunner AM Orthopädie, Orthopädische Chirurgie: die Störungen des Bewegungsapparates in Klinik und Paxis. 3. Auflage; Huber, Bern, Göttingen 1994

Delling G, Vogel M Pathomorphologie der Osteoporose. Schild H, Heller M (Hersg.): Osteoporose. Thieme, Stuttgart, New York 1992, 15-16

Delmas PD, Bjarnason NH, Mitlak BH, Ravoux AC, Ahah AS, Huster WJ, Draper M, Christiansen C (1997): Effects of raloxifene on bone mineral density, serum cholesterol concentrations, and uterine endometrium in postmenopausal women. N Engl J Med $\underline{337}$, $1641-1647$

Delmas PD, Eastell R, Garnero P, Seibel MJ, Stepan J (2000): The use of biochemical markers of bone turnover in osteoporosis. Committee of Scientific Advisors of the International Osteoporosis Foundation. Osteoporos Int 11, 2-17

Dervis E (2005): Oral implications of osteoporosis. Oral Surg Oral Med Oral Pathol Oral Radiol Endod 100, 349-356

Devlin H, Karayianni K, Mitsea A, Jacobs R, Lindh C, van der Stelt P, Marjanovic E, Adams J, Pavitt S, Horner K (2007): Diagnosing osteoporosis by using dental panoramic radiographs: The Osteodent Project. Oral Surg, Oral Med, Oral Pathol, Oral Radiol, Endodontics 104, 821-8

D`Ippolito G, Schiller PC, Ricordi C, Roos BA, Howard GA (1999): Agerelated osteogenic potential of mesenchymal stromal stem cells from human vertebral bone marrow. $\mathbf{J}$ Bone Miner Res $\underline{14}, 1115-22$

Doty SB (1981): Morphological evidence of gap junctions between bone cells. Calcif Tissue Int $\underline{33}, 509-512$

DVO (Dachverband Osteologie e. V.) (2009): DVO-Leitlinie 2009 zur Prophylaxe, Diagnostik und Therapie der Osteoporose bei Erwachsenen. Osteologie 18, 305-328 und www.dv-osteologie.org 
Eitel F, Klapp F, Dambe LT, Schweiberer L (1976): Revaskularisierung hypertrophischer Pseudarthrosen nach Druckplattenosteosynthese. Langenbecks Arch Chir Suppl Chir Forum $\underline{76}, 299$

El-Shinnawi UM, El-Tantawy SI (2003): The effect of alendronate sodium on alveolar bone loss in periodontitis (clinical trial). J Int Acad Periodontol 5: 5-10

Ettinger B, Black DM, Mitlak BH, Knickerbocker RK, Nickelsen T, Genant HK, Christiansen C, Delmas PD, Zanchetta JR, Stakkestad J (1999): Reduction of vertebral fracture risk in postmenopausal women with osteoporosis treated with raloxifene: results from a 3-year randomized clinical trial. Multiple Outcomes of Raloxifene Evaluation (MORE) Investigators. JAMA $\underline{282}, 637-645$

Felder-Puig R, Piso B, Guba B, Gartlehner G (2009): Kyphoplastie und Vertebroplastie bei osteoporotischen Wirbelkörperkompressionsfrakturen. Der Orthopäde $\underline{38(7)}$, 606-615

Felsenberg D, Hoffmeister B, Amling M, Fratzl P (2006): Onkologie: Kiefernekrosen nach hoch dosierter Bisphosphonattherapie. Dtsch Ärztebl 46, 103

Franke J, Clarenz P, Dören M (1996): Bericht der interdisziplinären Leitlinienkommission zur Diagnostik der Osteoporose. Osteologie $\underline{5}$, 162-173

Fröhlke A Untersuchungen zum Knochenstoffwechsel am immunkastrierten MinipigErprobung eines nicht invasiven Osteoporosemodells. Vet. Med. Diss. München 2009

Frost M (1969): Tetracycline-based histological analysis of bone-remodelling. Calcif Tissue Res $\underline{3}, 211$

Garnero P, Hausherr E, Chapuy MC, Marcelli C, Grandjean H, Muller C, Cormier C, Breart G, Meunier PJ, Delmas PD (1996): Markers of bone resorption predict hip fracture in elderly women: the EPIDOS Prospective Study. J Bone Miner Res 11, 1531-1538 
Garnero P, Sornay-Rendu E, Claustrat B, Delmas PD (2000): Biochemical markers of bone turnover, endogenous hormones and the risk of fractures in postmenopausal women: the OFELY Study. J Bone Miner Res 15, 1526-1536

Gasser JA, Ingold P, Grosios K, Laib A, Hammerle S, Koller B (2005): Noninvasive monitoring of changes in structural cancellous bone parameters with a novel prototype microCT. J Bone Miner Metab 23 Suppl, 90-96

Geurs NC (2007): Osteoporosis and periodontal disease. Periodontol 2000 44, 29-43

Gomes-Filho IS, Passos J de S, de Oliveira NF (2007): The association between postmenopausal osteoporosis and periodontal disease. J Periodontol $\underline{78}, 1731-1740$

Götte S, Dittmar K (2001): Epidemiology and costs of osteoporosis. Orthopäde $\underline{30}$, 402-404

Götz W Die Bedeutung der Osteoporose in der Zahnmedizin. Zahnarzt \& Praxis, Copyright (C) 2010 Spitta. All Rights Reserved

Green S, Walter P, Kumar V, Krust A, Bornert JM, Argos P, Chambon P (1986): Human oÖstrogen receptor cDNA: sequence, expression and homology to v-erb-A. Nature $\underline{320}, 134-139$

Grötz KA (2003): Zahnärztliche Betreuung von Patienten mit tumortherapeutischer KopfHals-Bestrahlung. Strahlenther Onkol 179, 275-8

Gruber R (2006): Entwicklung therapeutischer Konzepte zur Stimulation der Frakturheilung bei postmenopausaler Osteoporose. J Miner Stoffwechs $\underline{13}$, 77-81

Hao YL, Zhang G, Wang YS, Qin L, Hung WY, Leung K, Pei FX (2007): Changes of microstructure and mineralized tissue in the middle and late phase of osteoporotic fracture healing in rats. Bone $\underline{41}: 631-38$ 
Hara T, Sato T, Oka M, Mori S, Shirai H (2001): Effects of ovariectomy and/or dietary calcium eficiency on bone dynamics in the rat hard palate, mandible and proximal tibia. Arch Oral Biol $\underline{46}, 443-51$

Häussler B, Gothe H, Mangiapane S, Glaeske G, Pientka L, Felsenberg D (2006): Versorgung von Osteoporose-Patienten in Deutschland: Ergebnis der BoneEVA Studie. Dtsch Ärztebl 103(39), 2542-2548

Hoc S (2004): Osteoporose: Effiziente Therapie mit Alendronat. Dtsch Ärztebl 25, 101

Hofmann D (1992): Technischer Vorschlag zur Verbundosteosynthese. Eur J Trauma 18(5), 291-294

Horner K, Karayanni K, Mitsea A, Berkas L, Mastoris M, Jacobs R, Lindh C, van der Stelt P, Marjanovic E, Adams J et al. (2007): The Mandibular Cortex on Radiographs as a Tool for Osteoporosis Risk Assessment: The Osteodent Project. J Clin Densitometry 10, 138146

Jiang G, Matsumoto, Fuji A (2003): Mandible bone loss in osteoporosis rats. J Bone Miner Metab 21, 388-95

Klaiber E, Vogel W, Rako S (2005): A critique of the Women`s Health Initiative hormone therapy study. Fertil Steril $\underline{84}, 1589-1601$

Knese KH Stützgewebe und Skeletsystem. Springer-Verlag, Heidelberg 1997

Kolios L, Hörster AK, Sehmisch S, Malcherek MK, Rack T, Tezval M, Seidlova-Wuttke D, Wuttke W, Stuermer K, Stuermer EK (2009 a): Do Östrogen and Alendronate improve metaphyseal fracture healing when applied as osteoporosis prophylaxis? Calcif Tissue Int $\underline{86}$, 23-32

Kolios L, Sehmisch S, Daub F, Rack T, Tezval M (2009 b): Wirkung von PhytoÖstrogenen und Östrogen auf die Frakturheilung des osteoporotischen Knochens: Equol und Östrogen wirken unterstützend - Genistein hemmend. DGAV Forum $\underline{38}$, 305-307 
Komori T (1997): Target discruption of Cbfa1 results in a complete lack of bone formation owing to maturational arrest of oteoblast. Cell $\underline{89}, 755-764$

Komp M, Ruetten S, Godollas G (2004): Minimally invasive therapy for fuctionally unstable osteoporotic vertebral fracture by means of kyphoplasty. J Miner Stoffwechs $\underline{11}$, 1315

Kunchur R, Gross AN (2008): The oral health status of patients on oral bisphosphonates for osteoporosis. Austr Dental J $\underline{53}, 354-357$

Lane NE, Kumer J, Yao W, Breunig T, Wronski T, Modin G, Kinney JH (2003): Basic fibroblast growth factor forms new trabeculae that physically connect with pre-existing trabeculae, and this new bone is maintained with an anti-resorptive agent and enhanced with an anabolic agent in an osteopenic rat model. Osteoporos Int $\underline{14}, 374-382$

Lerner UH (2006): Inflammation-induced bone remodeling in periodontal disease and the influence of post-menopausal osteoporosis. J Dent Res $\underline{85}$ : 596-607

Lill CA, Gerlach UV, Eckhardt C, Goldhahn J, Schneider E (2002 a): Bone changes due to glucocorticoid application in an ovarectomized animal model for fracture treatment in osteoporosis. Osteoporos Int $\underline{13}, 407-414$

Lill CA, Fluegel AK, Schneider E (2002 b): Effect of ovarectomy, malnutrition and glucocorticoid application on bone properties in sheep: a pilot study. Osteoporos Int $\underline{13}, 480$ 486

Lin JT, Lane JM (2004): Osteoporosis: a review. Clin Orthop Relat Res $\underline{425}$, 126-134

Link TM Evaluation der Texturanalyseverfahren zur Osteoporosediagnostik. Med. Habilitationsschrift, Westfälische Wilhelms-Universität Münster 1997

Löffler G, Petrides PE: Biochemie und Pathobiochemie. 6. Auflage; Springer Verlag, Berlin 1998 
Manabe T, Mori S, Mashiba T, Cao Y, Kaji Y, Iwata K, Komatsubara S, Yamamoto T, Seki A, Norimatsu H (2009): Eel calcitonin (elcatonin) suppressed callus remodeling but did not interfere with fracture healing in the femoral fracture model of cynomolgus monkeys. J Bone Miner Metab 27: 295-302

Manolagas SC, Jilka RL (1995): Bone marrow, cytokines, and bone remodeling. Emerging insights into the pathophysiology of osteoporosis. N Engl J Med 332, 305-311

Manolagas SC, Kousteni C, Jilka RL (2002): Sex steroids and bone. Recent Prog Horm Res 57: 385-409

Marcus R, Wong M, Heath $\mathbf{H}$ (2002): Antiresorptive treatment of postmenopausal osteoporosis: comparison of study designs and outcomes in large clinical trials with fracture as an endpoint. Endocr Rev 23, 16-37

\section{McCann RM, Colleary G, Geddis C, Clarke SA, Jordan GR, Dickson GR, Marsh D}

(2008): Effect of osteoporosis on bone mineral density and fracture repair in a rat femoral fracture model. J Orthop Res 26: 384-93

Mc Clung MR, Wasnich RD, Hosking DJ, Christiansen C, Ravn P, Wu M, Mantz AM, Yates J, Ross PD, Sandora AC (2004): Early Postmenopausal Intervention Cohort Study. Prevention of postmenopausal bone loss: six-year results from the early postmenopausal intervention cohort study. J Clin Endocrinol Metab $\underline{89}$, 4879-85

Minne HW, Pfeifer M (2003): Diagnostik und Therapie der postmenopausalen Osteoporose. Klinikarzt $\underline{5}, 32$

Morgan EF, Mason ZD, Bishop G, Davis AD, Wigner NA, Gerstenfeld LC, Einhorn TA (2008): Combined effects of recombinant human BMP-7 (rhBMP-7) and parathyroid hormone (1-34) in metaphyseal bone healing. Bone Published online August 09, 2008; PMID: 18761113. 
Nikolaou VS, Efstathopoulos N, Kontakis G, Kanakaris NK, Giannoudis PV (2009): The influence of osteoporosis in femoral fracture healing time. Injury. Epub ahead of print, Mar 24.

O`Driscoll SW, Saris DB, Ito Y, Fitzimmons JS (2001): The chondrogenic potential of periosteum decreases with age. J Orthop Res $\underline{19}$, 95-103

Otto F (1997): Cbfa1, a candidate gene for cleidocranial dysplasia syndrome, is essential for osteoblast differentiation and bone development. Cell $\underline{89}, 765-771$

Otto S, Hafner S, Ehrenfeld M, Pautke C (2009): Bisphosphonat-assoziierte Osteonekrose des Unterkiefers. ZM 99, 2910-2914

Pallamar M, Friedrich M (2005): Aktuelle Diagnostik der Osteoporose. J Miner Stoffwechs $\underline{12}, 94-100$

Pavlidis T, Sabo D, Zahlten-Hinguranage G, Bernd I (2002): Die Verbundosteosynthese bei pathologischen Frakturen am Humerus. Z Orthop $\underline{49}$, 48-50

Pfeilschifter J (2003): Die Leitlinien des Dachverbands Osteologie zur Osteoporose. Osteologie 12, 54-61

Pietschmann P, Peterlik M (1999): Pathophysiologie und Therapie der Osteoporose. Radiologie 39, 228-234

Pollähne W, Hinne HW (2001): Epidemiologie, Diagnostik und klinisches Bild der Osteoporose. Bundesgesundheitsbl Gesundheitsforschung Gesundheitsschutz $\underline{44}$, 32-36

Popp AWE, Lippuner K (2005): Osteoporoseprävention bei der Frau heute. J Menopause $\underline{12}, 14-21$

Ravn P, Bidstrup M, Wasnich RD, Davis JW, Mc Clung MR, Blake A (1999): Alendronate and Östrogen-progestin in the long-term prevention of bone loss: four-year 
results from the early postmenopausal intervention cohort study. A randomized, controlled trial. Ann Intern Med $\underline{131}, 935-42$

Rawlinson SCF (1995): Calvarial and limb bone cells in organ and monolayerculture do not show the same early response to dynamic mechanical strain. J Bone Mineral Res $\underline{10}, 1225-$ 1232

Resch H (2004): Neues aus der Osteoporosetherapie. Menopause $\underline{3}$, 25-29

Riggs BL, Khosla S, Melton J (1998): A Unitary Model for Involutional Osteoporosis: Östrogen Deficiency Causes Both Type 1 and Type 2 Osteoporosis in Postmenopausal Woman and Contributes to Bone Loss in Aging Men. J Bone Miner Res $\underline{5}$ : 763-73

Riggs BL, Parfitt AM (2005): Drugs used to treat osteoporosis: the critical need for a uniform nomenclature based on their action on bone remodeling. J Bone Miner Res $\underline{20}$, 17784

Roschger P, Rinnerthaler S, Yates J, Rodan GA, Fratzl P, Klaushofer K (2001): Alendronate increases degree and uniformity of mineralization in cancellous bone decreases the porosity in cortical bone of osteoporotic women. Bone $\underline{29}, 185-91$

Ringe JD Osteoporose. Thieme Verlag, Stuttgart 1995

Rivard A, Fabre JE, Silver M, Chen D, Murohara T, Kearney M, Magner M, Asahara T, Isner JM (1999): Age-dependent impairment of angiogenesis. Circulation 99, 111-22

Scheidt-Nave C (2001): Die sozioökonomische Bedeutung der Osteoporose. Bundesgesundheitsblatt Gesundheitsforschung Gesundheitsschutz $\underline{44}, 41-51$

Scheidt-Nave C, Baum E, Dören M, Hadji P, Keck E, Minne H (2003): DVO-Leitlinie Osteoporose bei postmenopausalen Frauen. Osteologie 12, 63-91

Schenk R: Histology of fracture repair and non-union.Instructional Cours Bulletin. Davos AO/ASIF 1978 a 
Schenk R: Histomorphologische und physiologische Grundlagen des Skelet-wachstums. Weber BG, Brunner CH, Brunner CF (Hrsg): Die Frakturenbehandlung bei Kindern und Jugendlichen. Springer Berlin 31978 b

Schindler C, Kirch W (2008): Tumor und Osteoporose: So soll der Zahnarzt bei Bisphosphonatgabe verfahren. Zahnärztl Mitt $\underline{98(24)}$, 44-46

Schmidmaier G, Wildemann B, Bail H, Lucke M, Fuchs T, Stemberger A, Flyvberg A, Haas NP, Raschke M (2001): Local application of growth factors insulinlike growth factor-1 and Transforming growth factor- $\beta$ from a biodegradable poly (D,L-lactide) coating of osteosynthetic implants accelerated fracture healing in rats. Bone 28: 341-50

Seidlová-Wuttke D, Hesse O, Jarry H, Christoffel V, Spengler B, Becker T, Wuttke W (2003): Evidence for selective Östrogen receptor modulator activity in a black cohosh (Cimicifuga racemosa) extract; comparison with estradiol-17beta. Eur J Endocrinol 149, 351362

Strack WJ, Epker B (1995): Failure of osseointegrated dental implants after bisphosphonate therapy for osteoporosis- a case report. Int J Oral Maxillofac Implants $\underline{10}$, 74-6

Stürmer EK, Seidlová-Wuttke D, Sehmisch S, Rack T, Wille J, Frosch K, Wuttke W, Stürmer KM (2005): Standardized Bending and Breaking Test for the Normal and Osteoporotic Metaphyseal Tibia of the Rat: Effect of Estradiol, Testosterone, and Raloxifene. J Bone Miner Res $\underline{20}$, 89-96

Stürmer EK, Sehmisch S, Rack T, Wenda E, Seidlová-Wuttke D, Tezval M, Wuttke W, Frosch KH, Stuermer KM (2008 a): Östrogen And Raloxifene Improve Metaphyseal Fracture Healing In The Early Phase Of Osteoporosis. A New FractureHealing Model at the Tibia In Rat. Lang Arch Surg. Published online December 02, 2008; PMID: 19048282 


\section{Stürmer EK, Sehmisch S, Tezval M, Rack T, Kolios L, Daub F, Stuermer KM}

(2008 b): Supporting Effects of Parathyroid hormone (1-34), Raloxifene, and Östrogen on Early Fracture Healing in Osteoporotic Rats. J Orthop Res (submitted)

Syed F, Khosla S (2005): Mechanisms of sex steroids effects on bone. Biochem Biophys Res Commun 328(3): 688-96

Tanaka M, Toyooka E, Kohno S, Ozawa H, Eijiiri S (2003): Long-term changes in trabecular structure of aged rat alveolar bone after ovariectomy. Oral Surg, Oral Med, Oral Pathol, Oral Radiol, and Endodontics 95, 495-502

Tarakida A, Higuchi T, Mizunuma H (2007): Evidence of hormone replacement therapy for osteoporosis. Clin Calcium 18: 1434-41

Thompson DD, Simmons HA, Pirie CM, Ke HZ (1995): FDA Guidelines and animal models for osteoporosis. Bone $\underline{17}, 125-133$

Tsiridis E, Morgan EF, Bancroft JM, Song M, Kain M, Gerstenfeld L, Einhorn TA, Bouxsein ML, Tornetta P 3rd (2007): Effects of OP-1 and PTH in a new experimental model for the study of metaphyseal bone healing. J Orthop Res 25: 1193-203

White SC, Rudolph DJ (1999): Alterations of the trabecular pattern of the jaws in patients with osteoporosis. Oral Surg, Oral Med, Oral Pathol, Oral Radiol, and Endodontics $\underline{88}$, 62835

Wronski TJ, Lowry PL, Walsh CC, Ignaszewski LA (1985): Skeletal alterations in ovariectomized rats. Calcif Tissue Int $\underline{37}, 324-328$

Wüster C (1997): Klinik und Therapie der primären Osteoporosen; in: Metabolische Osteopathien; hrsg. V. Seibel MJ, Stracke H; Schattauer Verlag, Stuttgart, New York 1997 $162-193$

Wüster C, Ziegler R (1999): Metabolische Knochenerkrankungen. Thiemes Innere Medizin, $350-362$ 
Yang J, Farnell D, Devlin H, Horner K, Graham J (2004): The effect of ovariectomy on mandibular cortical thickness in the rat. Elsevier $\underline{33}, 123-129$

Yao W, Hadi T, Jiang Y, Lotz J, Wronski TJ, Lane NE (2005): Basic fibroblast growth factor improves trabecular bone connectivity and bone strength in the lumbar vertebral body of osteopenic rats. Osteoporos Int $\underline{16}, 1939-1947$

Zebaze R, Ghazem-Zadeh A, Bohte A, Iuliano-Burns S, Mirams M, Price RI, Mackie EJ, Seemann E (2010): Intracortical remodelling and porosity in the distal radius and post-mortem femurs of women: a cross-sectional Study. Lancet $\underline{375}$, 1729-36

Zhang X, Shu XO, Li H, Yang G, Li Q, Gao YT, Zheng W (2005): Prospective Cohort Study of Soy Food Consumption and Risk of Bone Fracture Among Postmenopausal Women. Arch Intern Med 165, 1890-1895

Zhou S, Zilberman Y, Wassermann K, Bain SD, Sadovsky V, Gazit D (2001):

Östrogen modulates Östrogen receptor alpha and beta expression, osteogenic activity, and apoptosis and mesenchymal stem cells (MSCs) of osteoporotic mice. J Cell Biochem Suppl. 36: $144-55$ 


\section{Tabellenverzeichnis}

Tab. 1: Klassifizierungsschema der Primären und Sekundären Osteoporose 3

Tab. 2: Bisphosphonate und deren Handelsnamen

\section{Abbildungsverzeichnis}

Abb. 1: Strukturformel von Alendronat $\quad 17$

Abb. 2: Zwick-Prüfmaschine 29

Abb. 3: Metallauflage mit Vertiefung zur Fixierung der Tibia 29

Abb. 4: In Methylmethacrylat eingebettete Rattentibia 31

Abb. 5: Schnittpräparat eines Tibiaknochens aus dem Methylmethacrylatblock 31

Abb. 6: Elastizitätswerte der Tibiae bei Biomechanischer Untersuchung 35

Abb. 7: Streckgrenze der Tibiae bei Biomechanischer Untersuchung (keine plastische

Verformung ersichtlich)

Abb. 8: Quantitativ, mittels Mikroradiographie, ausgewertete Kallusdichte (ventral) 36

Abb. 9: Quantitativ, mittels Mikroradiographie, ausgewertete Kallusdichte (dorsal) 37

Abb. 10: Quantitativ, mittels Mikroradiographie, ausgewertete Kallusdichte (endostal) 38

Abb. 11: Quantitativ, mittels Mikroradiographie, ausgewertete Kallusdicke (ventral) 39

Abb. 12: Quantitativ, mittels Mikroradiographie, ausgewertete Kallusdicke (dorsal) 39

Abb. 13: Quantitativ, mittels Mikroradiographie, ausgewertete Trabekeldichte (distal) 40

Abb. 14: Quantitativ, mittels Mikroradiographie, ausgewertete mittlere Trabekeldicke $\quad 41$

Abb. 15: Quantitativ, mittels Mikroradiographie, ausgewertete Dichte der

Trabekelkreuzungen 42

Abb. 16: Quantitativ, mittels Mikroradiographie, ausgewertete Kortikalisdichte (ventral) 43

Abb. 17: Quantitativ, mittels Mikroradiographie, ausgewertete Kortikalisdichte (dorsal) 43

Abb. 18: Quantitativ, mittels Mikroradiographie, ausgewertete Kortikalisdicke (ventral) 44

Abb. 19: Quantitativ, mittels Mikroradiographie, ausgewertete Kortikalisdicke (dorsal) 45 


\section{Danksagung}

Mein besonderer Dank gilt Frau Priv.-Doz. Dr. E. Stürmer für die Idee und Bereitstellung des Themas dieser Promotionsarbeit, das persönliche Engagement bei der Umsetzung neuer Ideen, der steten Hilfs- und Diskussionsbereitschaft und nicht zuletzt der persönlichen Betreuung, die diese Arbeit nicht nur ermöglichte, sondern mich stets neu motivierte.

Danken möchte ich auch Herrn Prof. Dr. W. Wuttke und Frau Dr. D. Seidlová-Wuttke für Unterstützung und Mitbetreuung des experimentellen Teils der Arbeit. 